\title{
A Review of Aerothermal Modeling for Mars Entry Missions
}

\author{
Michael J. Wright ${ }^{\dagger}$ \& Chun Y. Tang ${ }^{1}$ \\ NASA Ames Research Center, Moffett Field, CA 94035 \\ Karl T. Edquist, ${ }^{*}$ Brian R. Hollis ${ }^{\ddagger}$ \& Paul Krasa ${ }^{3}$ \\ NASA Langley Research Center, Hampton, VA 23681 \\ Charles A. Campbell ${ }^{\psi}$ \\ NASA Johnson Space Center, Houston, TX
}

\begin{abstract}
The current status of aerothermal analysis for Mars entry missions is reviewed. The aeroheating environment of all Mars missions to date has been dominated by convective heating. Two primary uncertainties in our ability to predict forebody convective heating are turbulence on a blunt lifting cone and surface catalysis in a predominantly $\mathrm{CO}_{2}$ environment. Future missions, particularly crewed vehicles, will encounter additional heating from shock-layer radiation due to a combination of larger size and faster entry velocity. Localized heating due to penetrations or other singularities on the aeroshell must also be taken into account. The physical models employed to predict these phenomena are reviewed, and key uncertainties or deficiencies inherent in these models are explored. Capabilities of existing ground test facilities to support aeroheating validation are also summarized. Engineering flight data from the Viking and Pathfinder missions, which may be useful for aerothermal model validation, are discussed, and an argument is presented for obtaining additional flight data. Examples are taken from past, present, and future Mars entry missions, including the twin Mars Exploration Rovers and the Mars Science Laboratory, scheduled for launch by NASA in 2011.
\end{abstract}

$B^{\prime}$

$C_{f}$

$C_{h}$

$h$

$J$

$k^{+}$

$\mathrm{M}_{\mathrm{a}}$

$M$

$q$

$R$

Re

$S c$

$T$

$V$

$\alpha$

$\beta$

\section{NOMENCLATURE}

non-dimensional mass blowing rate

skin friction coefficient

heat transfer coefficient

enthalpy

diffusion flux

non-dimensional roughness element size

Mach number

molecular weight

heat flux

universal gas constant

Reynolds number

Schmidt number

temperature

velocity

angle of attack

catalytic energy accommodation coefficient

\footnotetext{
${ }^{\dagger}$ Senior Research Scientist, Entry Systems and Technologies Division, MS 230-3. Associate Fellow AIAA.

${ }^{1}$ Senior Research Scientist, Aerothermodynamics Branch, Senior Member AIAA

*Aerospace Engineer, Atmospheric Flight \& Systems Analysis Branch, Senior Member AIAA.

$\ddagger$ Aerospace Engineer, Aerothermodynamics Branch. Senior Member AIAA.

${ }^{3}$ Project Manager, Senior Member AIAA

${ }^{\psi}$ Aerospace Engineer, Applied Aerosciences and CFD Branch, Associate Fellow AIAA
} 


\begin{tabular}{l}
$\gamma$ \\
$\kappa$ \\
$\lambda_{B}$ \\
$\rho$ \\
Subscripts \\
\hline 0 \\
$k$ \\
$\max$ \\
$r e l$ \\
$s$ \\
$T$ \\
$v e$ \\
$w$ \\
$\theta$
\end{tabular}

catalytic efficiency; flight path angle

thermal conductivity

blowing reduction parameter

density

\author{
smooth wall unblown value \\ internal energy mode index \\ maximum \\ relative \\ species index \\ turbulent \\ vibro-electronic \\ wall \\ momentum thickness
}

\section{InTRODUCTION}

Fueled by the search for extraterrestrial life, Mars has been the most frequently visited planet in the solar system. No less than thirteen attempts have been made to land on the surface of the red planet (see Table 1) by NASA, the European Space Agency (ESA), the Union of Soviet Socialist Republics (USSR), and the Russian Space Agency (RSA). As of this writing both NASA Mars Exploration Rovers - Spirit and Opportunity - are still functioning and returning scientific data after more than 72 months on the surface of the planet, and have uncovered compelling evidence that water once existed on the surface. The Phoenix Lander landed in 2008 and conducted a successful mission. One additional NASA mission is currently planned: the Mars Science Laboratory (MSL), with a launch currently scheduled for 2011. The European Space Agency is also planning an ambitious orbiter/rover mission called ExoMars to launch in the 2016 timeframe as part of the Aurora program. ${ }^{1}$ In addition, several NASA programs continue to plan future Mars missions: the Scout Program intends to launch a small mission in 2013, the Mars Technology Program is actively pursuing the development and selection of technologies to support the next generation of proposed Mars exploration, the Exploration Systems Mission Directorate has plans for robotic technology demonstration missions to Mars to lay the groundwork for possible human expeditions, and the NASA In-Space Propulsion program is investigating the possible use of aerocapture as a means of entering spacecraft more efficiently into Mars orbit than by propulsive deceleration. ${ }^{2}$ As future Mars exploration missions require increased landing performance (higher mass, smaller landing ellipse, higher elevations) the entry, descent, and landing phase in the thin Martian atmosphere will become increasingly challenging. ${ }^{3}$ As a consequence, the NASA Aeronautics Research Mission Directorate has made high mass planetary entry systems one of the key focus areas in its fundamental aeronautics program, and the Exploration Systems Mission Directorate has created a new technology project in this area.

Of all successful entries to date, only the first two (Viking I and II) have captured into orbit about the planet prior to entry. The decision to enter the Viking spacecraft from Mars orbit was made in part due to concerns about the severity of the entry heating environment in a (then) relatively unknown atmosphere. All subsequent missions have entered Mars directly on a hyperbolic trajectory, which leads to higher entry velocities, and therefore higher heat fluxes and heat loads, than an orbital entry. This decision lowers the total mass of the spacecraft by eliminating the fuel and propulsion system necessary to perform the Mars Orbit Insertion (MOI) maneuver. However, the thermal protection system (TPS), which shields the spacecraft from the intense heat generated during the entry, becomes more complex as the entry velocity (and therefore encountered heating rate and integrated heat load) increases. From Table 1 we see that relative entry velocities $\left(V_{\text {rel }}\right)$ for these missions have ranged from $5.5-7.5 \mathrm{~km} / \mathrm{s}$, with the exact value dependent on the interplanetary trajectory selected for the particular mission opportunity. ${ }^{4}$ Still higher velocities (on the order of 7-9 km/s) are possible for future crewed missions, ${ }^{5}$ for which the desire for reduced interplanetary cruise time may be more important than minimizing fuel consumption. Also shown in Table 1 for each mission are the entry date, flight path angle $(\gamma)$, and angle of attack $(\alpha)$, as well as the predicted zeromargin peak heating rate $\left(q_{\max }\right)$, and a note as to whether the entry vehicle heat shield included any engineering instrumentation from which in-situ measurements of the flight aerothermal environment could be obtained. 
Table 1. Summary of Mars entry missions

\begin{tabular}{|c|c|c|c|c|c|c|c|c|c|}
\hline Flight & Agency & Entry Date & $\begin{array}{c}V_{r e l} \\
(\mathbf{k m} / \mathbf{s})\end{array}$ & $\begin{array}{c}\alpha \\
\text { (deg) }\end{array}$ & $\begin{array}{c}\gamma \\
(\mathrm{deg})\end{array}$ & $\begin{array}{c}q_{\max } \\
\left(W / \mathrm{cm}^{2}\right)\end{array}$ & $\begin{array}{l}\text { Flight } \\
\text { Data? }\end{array}$ & Refs. & Notes \\
\hline Mars 2 & USSR & Nov. 27,1971 & 6.0 & 0 & & & ? & {$[127][128]$} & Lander crashed \\
\hline Mars 3 & USSR & Dec. 2, 1971 & 5.7 & 0 & & & $?$ & {$[127][128]$} & Operated for 20 seconds \\
\hline Mars 6 & USSR & Mar. 12, 1974 & 5.6 & & & & $?$ & [127] & Lander crashed \\
\hline Mars 7 & USSR & Mar. 6, 1974 & & & & & $?$ & [127] & Targeting error \\
\hline Viking I & NASA & Jul. 20, 1976 & 4.5 & 11 & -17 & 21 & Yes & [91] & \\
\hline Viking II & NASA & Sep. 3, 1976 & 4.5 & 11 & -17 & 21 & Yes & [91] & \\
\hline Mars96 & RSA & (1996) & & & & & No & [127] & Launch failure \\
\hline Pathfinder & NASA & Jul. 4, 1997 & 7.5 & 0 & -14 & 120 & Yes & {$[78]$} & \\
\hline MPL & NASA & Dec. 3, 1999 & 6.9 & 0 & -13 & 80 & No & [129] & Failed during final descent \\
\hline DS-2 & NASA & Dec. 3, 1999 & 6.9 & 0 & -13 & 200 & No & [130] & Lost after separation \\
\hline Beagle & ESA & Dec. 25,2003 & 5.6 & 0 & -16 & 75 & No & [131] & Lost after separation \\
\hline MER-A & NASA & Jan. 3, 2004 & 5.6 & 0 & -12 & 45 & No & [132] & \\
\hline MER-B & NASA & Jan. 24, 2004 & 5.6 & 0 & -12 & 45 & No & [132] & \\
\hline Phoenix & NASA & May 25, 2008 & 5.5 & 0 & -14 & 65 & No & [7] & \\
\hline MSL & NASA & 2012 & $\sim 5.9$ & $\sim 16$ & -14 & $\sim 200$ & Yes* & {$[40][137]$} & \\
\hline
\end{tabular}

* Instrumentation is slated to fly on the MSL heatshield

From Table 1 it can be seen that all previous entry vehicles with the exception of Viking I \& II have been designed as ballistic (zero angle of attack) entries. A more complex lifting entry is generally selected over ballistic only when it is necessary either to reduce the size of the landing ellipse, and/or to lengthen the descent timeline in order to provide sufficient time for the deceleration of a large payload in the tenuous atmosphere. (Both of these requirements are driving the lifting design of MSL). However, nominally ballistic entry vehicles also have angle of attack oscillations during the heating pulse. Such vehicles are designed and certified to a maximum angle of attack excursion at peak heating (typically $10 \mathrm{deg}$.). The entry angle of attack can have a significant impact on the predicted heating rates to the aeroshell, as well as transition to turbulence. ${ }^{6}$ As a consequence, full body threedimensional CFD calculations are typically employed during design and analysis to ensure that the thermal protection system is certified for the entire range of possible entry environments. However, even axisymmetric (zero angle of attack) simulations can show surprising results. Such calculations usually produce the highest afterbody heating levels, due to the predicted disk shock that forms in the wake ${ }^{7}$ and elevates heating at the rear stagnation point. Also, Gnoffo et al. ${ }^{8}$ have demonstrated that sonic line motion between the shoulder and sphere-cone junction due to real gas effects results in a hypersonic aerodynamic instability and corresponding aerothermal effects on the 70-deg sphere-cone Pathfinder geometry; a prediction later confirmed by entry data. ${ }^{9}$

The design of a low mass and reliable (low risk) TPS system for Martian atmospheric entry requires an accurate prediction of the aerothermal environment encountered by the spacecraft during entry. The peak heat flux (along with surface pressure and shear stress) will drive the selection of the thermal protection material for the heatshield, while the total integrated heat load determines the required thickness of TPS material. Laminar convective heating has been the primary TPS driver for all Mars missions to date. Turbulent heating, although a potential source for large uncertainty, has not been a significant issue for entries thus far. However, the trend toward larger, lifting, higher ballistic coefficient targeted landers (such as MSL) makes transition to turbulence and the resulting higher heating levels a significant design issue for future missions. The long slender (higher L/D) vehicles that will likely be required for future human missions will almost certainly encounter a turbulent heating environment. A second significant source of aeroheating uncertainty is catalytic heating in a dissociated $\mathrm{CO}_{2}$ atmosphere. Catalysis, in which the TPS surface facilitates the recombination of incident species, can be a large contributor to the total heating rate. No fully validated model currently exists to accurately predict the catalytic behavior of real Mars TPS materials under flight conditions, and thus conservative design assumptions are employed to bound this effect. A third source of uncertainty is localized heating effects due to penetrations or protrusions in the aeroshell, or transient heating due to Reaction Control System (RCS) plume interaction effects. Such singularities can promote early transition to turbulence and/or lead to localized hot spots on the TPS material that may exceed performance limits. A final potentially significant uncertainty is the amount of radiative heating, which is produced by the dissociated and ionized species in the hot nonequilibrium shock layer in front of the entering 
spacecraft. The integrated intensity of radiation from the shock layer that reaches the vehicle surface scales roughly linearly with the size of the entry vehicle, and approximately exponentially with the entry velocity. For all Mars missions to date the highest predicted level of shock layer radiative heating was for Pathfinder $\left(\sim 5-10 \mathrm{~W} / \mathrm{cm}^{2}\right)$, due to its relatively high $7.5 \mathrm{~km} / \mathrm{s}$ entry velocity. ${ }^{10}$ This level of radiative heating was still small as compared to the predicted convective heating of approximately $115 \mathrm{~W} / \mathrm{cm}^{2}$ for the Pathfinder entry. ${ }^{10-11}$ However, future missions, particularly crewed vehicles and their precursor heavy cargo missions, will be much larger and will have potentially higher entry velocities, which will lead in turn to much higher shock-layer radiation heating levels. Although shocklayer radiation for moderate velocity Earth entries is reasonably well understood, no validated nonequilibrium model currently exists to predict this effect in the Martian atmosphere.

The focus of the current work is to review the status of aerothermal analysis for Mars entries. Uncertainties and deficiencies inherent in the physical models used to predict these phenomena are explored, and a methodology is discussed by which many of those uncertainties can be quantified and ranked by their importance for TPS design. Examples are taken from past, present, and near-future Mars entry missions, including Pathfinder, the twin Mars Exploration Rovers (MER), Phoenix, and MSL. Capabilities of ground test facilities, including the hypersonic wind tunnels at NASA Langley as well as high enthalpy shock tunnels at the California Institute of Technology and the CalSpan University Buffalo Research Center, to support aeroheating validation for Mars entry missions are briefly summarized. Finally, the small amount of available engineering data obtained from the Viking, Pathfinder, and MER missions, which may be useful for aerothermal model validation, are discussed, and an argument is made for the need to obtain additional flight data in order to support the next generation of ambitious Mars missions. Note that only continuum flow analysis, using computational fluid dynamics (CFD), is presented. Analysis of rarefied (non-continuum) flows is usually performed using Direct Simulation Monte Carlo (DSMC) techniques, which are beyond the scope of this review. An excellent summary of the use of DSMC methods for high altitude blunt body computational aerothermodynamics is given by Moss and Price. ${ }^{12}$ It is important to note that, for most missions of interest that use rigid aeroshells, the majority of the heat pulse occurs in the continuum flow regime where traditional CFD methods are valid. However, the potential use of Inflatable Aerodynamic Decelerators (IADs) on future Mars missions may place increasing emphasis on the need for improvements to non-continuum flow models, since IADs decelerate higher in the atmosphere due to their lower ballistic coefficient. Future human missions to Mars will likely utilize a combination of aerocapture and direct entry strategies and the current work is a step along the way of establishing the fidelity of the analysis methods currently employed in the design of such vehicles.

\section{Physical Models}

The Martian atmosphere consists of approximately $97 \% \mathrm{CO}_{2}$ and $3 \% \mathrm{~N}_{2}$ by volume. Small amounts of other species (primarily Argon) are also present, but can usually be neglected. The high temperature flowfield behind the bow shock is a region where the gas heats and dissociates (and possibly ionizes) and the constituent species undergo additional chemical reactions. The atoms and molecules also become thermally excited as energy is transferred among the kinetic (translational), rotational, vibrational, and electronic modes via collisions. Our ability to understand and model the energy state of this nonequilibrium gas with reasonable fidelity is particularly important when predicting the radiation energy emanating from the excited atoms and molecules from the shock layer as well as the convective heating occurring at the surface.

This complex flowfield is typically modeled in thermochemical nonequilibrium, meaning that, in addition to the conservation equations for momentum and total energy, additional equations are solved for each species in the dissociated shock-layer as well as a combined vibro-electronic energy. An excellent review of the relevant conservation equations and their required source terms for this model is presented in Ref. 13 and revisited in Ref. 14; the results will only be briefly summarized here. In this formulation it is assumed that the vibrational and electronic modes of the gas are in equilibrium with each other, but not with the translational-rotational component. Free electrons, when present, are assumed to be in equilibrium with the vibro-electronic mode of the gas. This model therefore describes the flowfield with two temperatures; the translational-rotational $(T)$ and the vibro-electronic $\left(T_{v e}\right)$. Chemical reactions proceed at a finite rate, governed by the two temperatures in the flow. It should be noted that this two-temperature model was developed for air flows, based on limited shock tube data for $\mathrm{O}_{2}$ and $\mathrm{N}_{2}$ dissociation, ${ }^{15}$ and has since been applied to entries in other planetary atmospheres with minimal validation. Molecules are generally assumed to be created and destroyed at the local average mixture internal energy (nonpreferential dissociation). The energy exchange between the translational-rotational and vibrational-electronic modes is modeled using a Landau-Teller formulation assuming simple harmonic oscillators. Vibrational relaxation times are obtained from Millikan and White ${ }^{16}$ for most species. However, relaxation times for the vibrational modes of $\mathrm{CO}_{2}$ are taken from Camac, ${ }^{17}$ and those for $\mathrm{CO}$ and are taken from Park. ${ }^{18}$ Because $\mathrm{CO}_{2}$ and $\mathrm{CO}$ relax very quickly and are dominant shock layer species, the level of thermal nonequilibrium in the flowfield is small for most 
cases, although it should be modeled for completeness. More realistic vibrational relaxation models have also been proposed. ${ }^{19-20}$ These models are in routine use for $\mathrm{CO}_{2}$ laser applications, but in general have not been employed for Mars entry simulations due to the small amount of predicted thermal nonequilibrium in the flowfield. Even more complex nonequilibrium models are certainly possible, but in many cases the additional source terms required by such models are poorly characterized, and thus can introduce additional uncertainty into the final equation set.

Thermodynamic properties of the component shock-layer species (up to $20,000 \mathrm{~K}$ ) are typically taken from Gordon and McBride. ${ }^{21}$ More recent work by Capitelli et al. ${ }^{22}$ has extended the usable temperature range to 50,000 K. Capitelli et al. ${ }^{22}$ also demonstrated that the Gordon and McBride curve fits are inaccurate for monatomic species at temperatures above $10,000 \mathrm{~K}$, primarily because the tabulated data of Gurvich et al. ${ }^{23}$ on which they are based do not include a sufficient number of excited states in the electronic partition function for such elevated temperatures. Therefore, it is recommended that the Gordon and McBride data, particularly for monatomic species, be augmented by that of Capitelli et al. above $10,000 \mathrm{~K}$ for high temperature applications.

A review of the nonequilibrium chemical kinetics of a shock heated mixture of $\mathrm{CO}_{2}-\mathrm{N}_{2}-\mathrm{Ar}$ was presented by Park et al. ${ }^{18}$ for an 18-species gas $\left(\mathrm{CO}_{2}, \mathrm{NCO}, \mathrm{CO}, \mathrm{CO}^{+}, \mathrm{CN}, \mathrm{NO}, \mathrm{NO}^{+}, \mathrm{N}_{2}, \mathrm{O}_{2}, \mathrm{O}_{2}^{+}, \mathrm{C}_{2}, \mathrm{~N}, \mathrm{C}, \mathrm{C}^{+}, \mathrm{O}, \mathrm{O}^{+}, \mathrm{Ar}, \mathrm{e}\right)$ with ionization. Park et al. proposed a 33-reaction mechanism to be used for high velocity Mars entries, based on a mixture of shock tube data and rates taken from the combustion literature. Mitcheltree and Gnoffo ${ }^{24}$ subsequently presented a reduced 8-species $\left(\mathrm{CO}_{2}, \mathrm{CO}, \mathrm{NO}, \mathrm{N}_{2}, \mathrm{O}_{2}, \mathrm{~N}, \mathrm{C}, \mathrm{O}\right)$ 13-reaction mechanism that neglected ionization and several trace neutral species. The rates for those reactions common to the Park et al. mechanism were taken directly from. ${ }^{18}$ For entry velocities below about $8 \mathrm{~km} / \mathrm{s}$, the level of ionization in the flowfield will be small. Therefore, it is expected that the heat flux computed using the Mitcheltree and Gnoffo 8-species model should be sufficient to simulate the major characteristics of the flowfield. However, the more detailed 18-species model should be employed for cases with significant shock-layer radiation, because it includes CN (a significant radiator), as well as free electrons, which are efficient at the collisional excitation of atoms and molecules. An ionized flow model is also required for the computation of communication blackout duration during the entry. Backward rates are generally computed via a minimized Gibb's free energy approach using the species thermodynamic properties of Ref. 21 or Ref. 22, assuming that the principle of detailed balance holds. It should be noted that while the rates proposed by Park et al. ${ }^{18}$ were the best available at the time, the rates of many of these reactions have not been directly measured at conditions relevant to Martian entry. Some are determined approximately from indirect observations, while others are pure estimates, ${ }^{18}$ which make them potentially significant sources of uncertainty. In particular, the effects of thermal nonequilibrium on the reaction rates and subsequent energy disposal mechanisms are not well understood. In addition, the models currently employed consider only reactions between ground state species, ignoring the possibility of the formation of excited state molecules via preferred recombination pathways. No comprehensive sensitivity analysis of these kinetic mechanisms has been done to date for Mars reentry applications. NASA's Fundamental Aeronautics Program is currently investing in ab initio calculations for some of the key elemental interactions of interest, ${ }^{142}$ but additional research in this area, prioritized by sensitivity analyses, is needed.

Robust models of the transport properties of a multi-species reacting gas mixture are necessary to ensure accurate predictions of surface properties, especially heat transfer and shear stress. The viscosity and thermal conductivity of the gas mixture are typically modeled using binary collision-integral based mixing rules such as those presented by Gupta et al., ${ }^{25}$ which have been shown to be reasonable approximations of the more accurate Chapman-Enskog relations. ${ }^{26}$ The self-consistent effective binary diffusion (SCEBD) method ${ }^{27}$ or equivalent $^{28}$ is used to compute the species ordinary (mass) diffusion coefficients. This method allows for the variations between the diffusion coefficients of different species to be accurately modeled without sacrificing the requirement that the diffusion velocities sum identically to zero, and has been shown ${ }^{28}$ to accurately model the true multi-component diffusion velocities. Early simulations generally employed a constant Schmidt number based diffusion model, ${ }^{29}$ in which all species diffusion coefficients were assumed to be equal. This model, though lower in fidelity than the SCEBD approach, can produce reasonable results if the Schmidt number is tailored for the entry conditions of interest, although it does not allow elemental demixing to occur, ${ }^{30}$ which can affect surface chemistry models. For weakly ionized flows the ambipolar diffusion assumption is commonly employed; therefore an additional correction to the diffusion fluxes is required to satisfy the requirement of zero current density in the flow. ${ }^{31}$ A frequently referenced simplistic model for the ambipolar diffusion effect is to multiply the diffusion coefficients of all ions by two, but this method has been shown to be inaccurate for flows with more than one ionized species, ${ }^{31}$ and in general the more exact current balance expression should be used. Thermal and pressure diffusion effects are generally small in comparison to ordinary diffusion and can be neglected. The resulting transport property expressions each require as input collision integral data for each binary interaction in the gas mixture. The best available values for the required collision integrals have been tabulated as a function of temperature in the recent critical reviews of Wright 
et al. ${ }^{32-33}$ for all ground-state binary interactions in the weakly ionized Mars atmosphere mixture. These reviews include recommended values as well as estimated uncertainties for each interaction.

There are many models proposed in the literature to simulate turbulent hypersonic flows, ranging from zeroequation models that estimate the eddy viscosity with a simple algebraic expression, to more complex Reynolds averaged Navier-Stokes (RANS) models which require the solution of one, two, or even three additional conservation equations. For Mars entries, turbulent simulations have typically been computed using either the Baldwin-Lomax algebraic turbulence model ${ }^{34}$ or the two-equation shear stress transport (SST) model of Menter. ${ }^{35}$ Both models were developed originally for incompressible flows and include compressibility corrections to extend their use into the supersonic-hypersonic regime. ${ }^{36}$ The Baldwin-Lomax model is frequently used to compute design turbulent heating for Mars entry simulations, but its accuracy in predicting turbulent heating levels on lifting blunt cones at flight conditions is not well characterized. In particular, algebraic models are not accurate for separated flows or the simulation of boundary layers with a strong pressure gradient, either favorable (such as in separated wakes or regions of rapid expansion), or adverse (such as in shock boundary layer interactions). The SST model was shown to be reasonably accurate for a variety of hypersonic flows in a recent turbulence model validation study. ${ }^{36}$ However, no flight data exist to permit validation of any turbulence model in a Martian entry environment. It should also be noted that all of the turbulence models discussed herein are design for the prediction of smooth-wall turbulence. Possible augmentation of the baseline turbulent heating levels due to ablation induced distributed surface roughness are not accounted for directly in these models. Finally, for reacting turbulent flows the predicted heating is sensitive to the choice of the turbulent Schmidt number $\left(S c_{T}\right)$, which enhances mixing in the boundary layer and increases the rate of diffusion of catalytic reactants to the surface. Unfortunately, the correct value of $S c_{T}$ for high enthalpy wall-bounded flows is currently unknown. Values in the range $0.5 \leq S c_{T} \leq 1.0$ are typically used in the literature, with smaller values resulting in higher heating rates. In order to conservatively bound the turbulent heating rate, a value of $S c_{T}=0.5$ is recommended for design purposes. RANS turbulence models that include an extra differential equation for the direct solution of a variable turbulent Schmidt number are currently under development for scramjet applications; ${ }^{37}$ such models should be explored further in order to determine their applicability to Mars entry simulations. More complex turbulence models, such as Direct Numerical Simulation (DNS), Large Eddy Simulation (LES), and Detached Eddy Simulation (DES) remain too expensive for engineering design analysis, although recent developments, particularly in DES, may make them tractable alternatives to RANS in the future. ${ }^{142}$

Although several engineering models have been proposed for estimating the onset of turbulent transition, none are well validated for blunt ablating aeroshells, particularly in a Mars environment. Schneider ${ }^{38}$ recently $^{2}$ published a review of existing flight transition data on capsules, but these data have not been used to develop new correlations at this time. As a consequence, designers have typically relied on simple correlations, such as a critical value of the momentum thickness Reynolds number $\left(\mathrm{Re}_{\theta}\right)$, to estimate transition in flight. ${ }^{39-40}$ The vehicle is generally assumed to be completely turbulent once the critical value of $\mathrm{Re}_{\theta}$, or $\mathrm{Re}_{\theta}$ divided by the edge Mach number $\left(\operatorname{Re}_{\theta} / \mathrm{M}_{e}\right)$, is reached in an attempt to ensure that the design is conservative. These relatively crude approximations have not been an issue for previous Mars missions since turbulent heating was not expected, but future missions may require a more accurate assessment of turbulent transition and the resulting heating levels due to larger aeroshell size and and/or the use of slender mid L/D configurations. One important consideration is that the traditional $\mathrm{Re}_{\theta}$ based transition criterion was developed to correlate geometry-dependent smooth-body axial transition. As such, its general applicability is in question, ${ }^{41}$ particularly for a blunt aeroshell for which the dominant mode will likely be bypass transition caused by distributed roughness due to ablation of the thermal protection material on the heatshield, ${ }^{42-43}$ and/or by blowing of pyrolysis gases into the boundary layer. ${ }^{44}$ New transition criteria, which account for each of these effects in a physically based formulation, must be developed if transition is an important design characteristic for future Mars entry vehicles. Hybrid correlations, ${ }^{43}$ which include roughness effects with a smooth wall limit, have been developed to correlate roughness dominated blunt body transition However, these correlations must be extended to include blowing effects, which can dominate roughness at high heating levels on pyrolizing TPS. Another consideration is that ballistic or low lift blunt bodies typically exhibit axial transition, while for lifting bodies at angle of attack crossflow effects can also be an important transition mechanism. ${ }^{39}$ The parabolized stability equations (PSE) have been used for some time to predict transition on slender bodies, ${ }^{45}$ and two recent papers predicted strong instabilities on the leeside of the MSL aeroshell ${ }^{46,149}$ at both tunnel and flight conditions. However such methodologies cannot currently be directly used to predict roughness or blowing induced transient growth leading to bypass transition. ${ }^{47}$ The recent Orbiter boundary layer transition experiment ${ }^{143}$ has provided a wealth of new data on transition induced by discrete roughness elements in a high enthalpy air flow, but the results must be extended to the conditions and geometries anticipated for Mars entry applications. Recent efforts motivated by the acquisition of Orbiter discrete protuberance BLT are also being 
performed to demonstrate PSE simulation capabilities ${ }^{150}$ on a smooth Orbiter at flight conditions. Additional work in this area, particularly the addition of distributed roughness and blowing effects to the models, should be pursued.

Once the ablation process is initiated, the exposed outer surface of the TPS forms a char layer which is both porous and rough. The porosity of the char layer enables the transport of pyrolysis gases generated from thermal decomposition from the TPS interior to the exposed surface. The exit of these pyrolysis gases into the boundary layer reduces the skin friction and convective heat transfer due to the transpiration effect; however, the distributed roughness of the exposed char layer can counter this reduction. Substantial work on transpiration cooling of laminar boundary layers was accomplished both analytically and experimentally during the 1950's on projects associated with various aspects of missile development. Emmons and Leigh ${ }^{48}$ tabulated solutions of the incompressible boundary layer subject to specified transpiration that are suitable for validation of modern computational methods. The combined effects of roughness and transpiration on turbulent boundary layers have subsequently been studied experimentally by a number of investigators. ${ }^{49-52}$ Inclusion of transpiration and roughness effects into turbulence models, used by modern computational methods and suitable for hypersonic flows, are described by Cebeci and Bradshaw $^{53}$ and also Wilcox. ${ }^{54}$ As always, any implementation into a computational method requires validation against either analytical solutions or credible experimental data. The effects of transpiration and roughness can be accounted for in the TPS design process by one of two methods:

(a) The wall boundary condition, and turbulence model as appropriate, of the external flow solver can be modified to incorporate these effects;

(b) The skin-friction and convective heat transfer obtained from smooth-wall, non-ablating Navier-Stokes solution can be adjusted by engineering correlations prior to use, typically in a TPS material response code. Current practice for heatshield design follows the latter course, in which a TPS material response code is used to compute blowing mass-transfer rates and adjust the convective heating from the external flow-solver to account for the transpiration effect by engineering correlation methods, specifically: ${ }^{55}$

$$
\frac{C_{h}}{C_{h 0}}=\frac{C_{f}}{C_{f 0}}=\frac{\ln \left(1+2 \lambda_{B} B^{\prime}\right)}{\left(1+2 \lambda_{B} B^{\prime}\right)}
$$

where $B^{\prime}$ is a dimensionless blowing rate. The blowing correction factor $\lambda_{B}=0.5$ if the external boundary layer flow is laminar, and is adjusted so as to give reduced blowing effectiveness for turbulent flow. Such adjustment may implicitly incorporate roughness effects associated with ablative materials. It has also been proposed ${ }^{56}$ that strong blowing of turbulent pyrolysis products due to excessive ablation can augment, rather then reduce, turbulent heating levels if the pyrolysis gas itself becomes turbulent in the char layer. However, this effect is not likely to be a concern for the moderate heating and wall blowing rates encountered during Mars entry missions.

Should the flow become turbulent, the distributed roughness of the char layer may enhance the skin friction and heat transfer above smooth-wall levels. If roughness elements extend no further than the viscous sublayer, the flow is considered to be hydraulically smooth with no enhancement. However, if the roughness elements project into the turbulent buffer layer, the velocity profile is affected and skin friction ${ }^{57-58}$ and convective heat transfer ${ }^{59}$ levels increase according to:

$$
\begin{aligned}
& C_{f} / C_{f 0}=1.0+0.9\left(\log \left(k^{+}\right)-1.0\right) \quad \text { if } \mathrm{k}^{+}>10 \\
& \begin{array}{ll}
=1.0 & \text { if } \mathrm{k}+<10
\end{array} \\
& C_{h} / C_{h 0}=1.0+0.6\left[\left(C_{f} / C_{f 0}\right)-1.0\right]
\end{aligned}
$$

The roughness enhancement to heat transfer is reduced from the skin friction enhancement since a portion of the skin friction is due to profile drag of the roughness elements. Use of these relations requires a mapping of the physical geometry and spacing of the distributed roughness elements to an equivalent sand roughness, ${ }^{60}$ which is used to calculate the non-dimensional roughness parameter $k^{+}$. For many practical situations as might be encountered by TPS ablation, the mapping of actual roughness to equivalent sand roughness will range from roughly 1:1 or lower. Recent work by the Crew Exploration Vehicle (CEV) Aerosciences Project (CAP) has tested the validity of these historical correlations via ground testing in several hypersonic and high enthalpy facilities. The results of this work, when made available in the open literature, should be used to update the correlations employed for heating augmentation at Mars relevant conditions.

The separated afterbody flowfield will also likely transition from a laminar to a turbulent flow at some point during the entry. In a separated base flow, wake transition begins in the far wake and travels upstream with 
increasing freestream Reynolds number ( $R e$ ) until reaching the neck, where it is (temporarily) stopped by the adverse pressure gradient. ${ }^{61}$ In the near-wake (base) region transition begins in the separation shear layer. ${ }^{62}$ Lees ${ }^{63}$ gives a transition correlation for the free shear layer behind a hypersonic blunt body. This criterion is based on freeflight data, but does not include effects of upstream ablation product gas injection, ${ }^{64}$ which can destabilize the forebody boundary layer and could also affect the shear layer and separated flow region via entrainment. Near-wake transition can also be instigated by the ingestion of a turbulent forebody boundary layer into the wake core. Unfortunately, no validated turbulence models exist for the prediction of separated afterbody flowfields. In fact, the accuracy of all RANS based models is in question for hypersonic separated flows. In addition, such separated flows are inherently unsteady, requiring validated high-order time integration techniques (such as the dual-timestepping approach) for accurate simulation. Therefore, turbulent heating augmentation factors of $\sim 100 \%$ are typically carried as an aeroheating uncertainty margin in the design for entries where early wake transition cannot be ruled out. These factors are based on limited (and possibly mis-interpreted) flight data from the Apollo and Viking missions. While such flows are typically beyond the capabilities of more accurate turbulence models such as DNS or LES due to the large Reynolds number (and correspondingly high computational cost), hybrid methods such as Detached Eddy Simulation (DES) have shown promise for supersonic base flows. ${ }^{65}$ DES has recently been applied with some success to hypersonic afterbodies. ${ }^{66,144}$ However, much more work is required to validate this methodology and to determine the efficacy (or lack thereof) of RANS models for Mars entry afterbody heating simulations.

Finally, it is well known that Mars is subject to both localized and planet-wide dust storms. These storms occur at irregular intervals, with an average frequency of one every 3-4 years. Given average storm duration and the residence time of dust particles in the high atmosphere after a storm has passed, prior analysis has indicated that there is a $2-4 \%$ chance of encountering significant quantities of high-altitude atmospheric dust during a given entry mission. ${ }^{67}$ The possible presence of dust particles in the upper atmosphere is an aeroheating/TPS design concern because of the potential for enhanced mechanical erosion of the heatshield during the entry. Such erosion would need to be compensated for with additional margin (thickness) on the TPS. In addition, mechanical erosion may lead to a distributed roughness pattern on the ablator surface that could induce early turbulent transition or higher turbulent heating levels. Recent analysis ${ }^{68}$ has shown that dust erosion should be negligible for moderate velocity direct entries. However, dust erosion may still be an issue for long duration (such as lifting entry or aerocapture), multiple pass, or high velocity entry trajectories. It may be possible to "wait out" dust storms on eventual human exploration missions by capturing into Mars orbit and deferring entry until conditions are favorable. However, this option is not possible for science missions due to mass limitations, and it does not address the need for robust entry systems during the aerocapture phase into orbit.

It is important to note that the physical models discussed in this section are not the only models employed for Martian entry simulations; they are simply the models that are most commonly used in recent years by NASA and their prime contractors for entry vehicle design. The current state of the art of planetary entry aerothermal models is in a constant state of flux; as new experimental data are obtained or theoretical refinements are made, the models are periodically updated. As such, the models presented here should be considered current NASA best practices, but are likely to change in coming years, particularly in response to rigorous uncertainty and sensitivity analyses that identify the key areas for which improvements will benefit future mission design, or the future availability of engineering flight data that can be used to perform rigorous validation of the models employed.

\section{SURFACE REACTIONS}

Surface catalysis is of primary importance in the design of a non- or weakly ablating TPS material. The physical mechanism that governs catalytic recombination on the surface of a TPS material is poorly understood, in part due to difficulties in performing in-situ surface diagnostics at flight-appropriate temperatures and pressures. Consequently, modeling of catalytic reactions at the surface has been relatively primitive. Catalytic processes are usually modeled as zeroth order reactions limited by the flux of reactants to the surface, as in

$$
J_{s, w}=\dot{w}_{s}
$$

In this equation, the diffusive flux of species $s$ to the wall $\left(J_{s, w}\right)$ is balanced by the rate of production or destruction of the species at the wall $\left(\dot{w}_{s}\right)$. The source term is modeled as the product of a zeroth order reaction rate and the catalytic efficiency (fraction of incident atoms which will recombine on contact with the surface). For example, for the single homogeneous catalytic reaction $\mathrm{N}+\mathrm{N} \rightarrow \mathrm{N}_{2}$, the source terms are given by

$$
\dot{w}_{N}=\rho_{N} \gamma_{N}\left(T_{w}\right) \sqrt{\frac{R T_{w}}{2 \pi M_{N}}} ; \quad \dot{w}_{N_{2}}=-\dot{w}_{N}
$$


It is well known that wall catalysis can be a significant source of convective heating for many reentry applications. This influence occurs because catalytic processes also affect the surface energy balance, which includes a term for the chemical energy deposited on the wall by the recombination process. The surface energy balance is typically modeled as

$$
q_{w}=\kappa \nabla T_{w}+\sum_{k} \kappa_{k} \nabla T_{k w}+\sum_{s} J_{s w} \beta_{s} h_{s}
$$

where the second term is summed over the $k$ nonequilibrium internal energy modes, and the final term encompasses the energy transfer to the surface due to exothermic catalytic reactions.

The factor $\beta_{s}$ in Eq. (6) is the energy (or chemical) accommodation coefficient, which governs the fraction of the recombination energy that is transferred to the surface. ${ }^{69}$ Detailed experimental and theoretical analyses have shown that molecules formed at the surface of a TPS material are usually highly vibrationally and rotationally excited as compared to the surrounding flow, leading to an energy accommodation coefficient that is less than one. However, the energy accommodation coefficient is typically taken to be equal to one in CFD models, because most available experimental catalysis data are based on heat flux rather than direct species detection, and because the assumption of $\beta=1$ is assumed to be conservative since it results in the maximum heat release on the surface for a given catalytic efficiency. For example, Stewart ${ }^{70}$ has characterized the catalytic properties of several NASA TPS materials in dissociated air using a combination of arc jet testing at high temperature and a side-arm reactor (diffusion tube) at low temperature. In Stewart's analysis it was assumed that the energy accommodation coefficient was equal to one, and catalytic efficiencies $(\gamma)$ at high temperature were determined via comparison of the measured heat flux to a reference model of known catalycity. The quantity that Stewart reports as a catalytic efficiency is therefore a combination of $\gamma$ and $\beta$ as defined in Eqs. (5) and (6).

Catalytic properties of materials in dissociated $\mathrm{CO}_{2}$ have not been characterized as extensively as in air, although some recent studies ${ }^{71-76}$ have explored possible mechanisms on certain materials. However, none of these studies have examined materials and conditions relevant to previous or planned NASA missions. Additional work in this area, particularly in quantifying the value of the energy accommodation coefficient, is needed. In the absence of a validated model, four simplified catalytic reaction mechanisms are commonly employed in the literature. These models are discussed briefly here.

The simplest model that is commonly used is to assume that the surface is non-catalytic. This model produces the lowest possible heating rates, and as such is not often employed for design purposes, as it is likely nonconservative. At the other extreme is the "supercatalytic" wall model, ${ }^{29}$ in which the gas composition at the wall is forced to be equal to its lowest chemical enthalpy state (in this case pure $\mathrm{CO}_{2} / \mathrm{N}_{2}$ ). This model is not entirely physically based, because finite-rate surface reactions are not modeled. However, the supercatalytic assumption serves as a useful limiting case because it is conservative: essentially all of the available chemical enthalpy in the dissociated boundary layer is recovered at the wall, regardless of the actual chemical composition. This was the model employed for MER and Phoenix ${ }^{7}$ and currently baselined for $\mathrm{MSL}^{77}$ design.

The Mitcheltree catalysis model, ${ }^{78}$ developed during the Mars Pathfinder program, is also often employed. In the Mitcheltree model, $\mathrm{CO}_{2}$ recombination at the surface is modeled as a two-step reaction involving $\mathrm{CO}$ molecules and $\mathrm{O}$ atoms, with two parallel paths given by:

$$
\begin{array}{llll}
\mathrm{O}+(s) & \rightarrow \mathrm{O}_{\mathrm{s}} ; \quad \mathrm{CO}+\mathrm{O}_{\mathrm{s}} & \rightarrow \mathrm{CO}_{2} \\
\mathrm{CO}+(\mathrm{s}) \rightarrow \mathrm{CO}_{\mathrm{s}} ; \quad \mathrm{O}+\mathrm{CO}_{\mathrm{s}} \rightarrow \mathrm{CO}_{2}
\end{array}
$$

where $(s)$ is a surface adsorption site and the subscript $s$ indicates an adsorbed species. The mechanism is assumed to follow an Eley-Rideal process, in which an incident gas-phase species recombines directly with a previously adsorbed atom or molecule. The rate of recombination is bounded by the diffusion rate of the required reactants $O$ and $\mathrm{CO}$ to the surface; the slower of these two processes becomes the rate-limiting step. Potential surface reactions that form $\mathrm{O}_{2}$ and $\mathrm{N}_{2}$ are neglected. The heat transfer predicted by the Mitcheltree model will be close to that predicted by the supercatalytic wall for the case where the dominant boundary layer species are $\mathrm{O}$ and $\mathrm{CO}$, but a lower heat transfer will be predicted if $\mathrm{O}_{2}$ is present in significant quantities at the boundary layer edge, since $\mathrm{O}_{2}$ is considered chemically inert in the Mitcheltree (but not in the supercatalytic) model.

The fourth model is based on the fact that the $\mathrm{CO}+\mathrm{O}$ oxidation reaction has not been observed to occur in ground-based experiments at low temperature ${ }^{72,76}$ and the $\mathrm{CO}+\mathrm{O}_{2}$ reaction mechanism is only known to occur on platinum group metals at temperatures around $250{ }^{\circ} \mathrm{C} .{ }^{79}$ Therefore this model assumes that $\mathrm{CO}_{2}$ does not form on the surface of a TPS material at Martian entry conditions and only homogeneous surface reactions are possible, resulting in the following surface kinetics: 


$$
\begin{aligned}
\mathrm{O}+\mathrm{O} & \rightarrow \mathrm{O}_{2} \\
\mathrm{~N}+\mathrm{N} & \rightarrow \mathrm{N}_{2}
\end{aligned}
$$

This model leads to significantly lower heating than the Mitcheltree or supercatalytic models, since the chemical enthalpy contained in $\mathrm{CO}$ molecules is not recovered at the wall. It is important to note that typical surface temperatures encountered during Mars entry $\left(\mathrm{T}_{\mathrm{w}}=1500-2500^{\circ} \mathrm{C}\right)$ are much higher than those in any of the prior $\mathrm{CO}_{2}$ catalysis testing discussed in this section, and thus the extrapolability of those results to flight conditions is certainly in question.

Figure 1 shows the turbulent heat transfer predicted at the peak heating point of an early MSL design trajectory using each of these models. The peak heat flux ranges from about $47 \mathrm{~W} / \mathrm{cm}^{2}$ for the non-catalytic surface to $125 \mathrm{~W} / \mathrm{cm}^{2}$ for the supercatalytic case, a factor of 2.5 difference. More recent MSL design trajectories show higher total heat flux but nearly the same ratio between non-catalytic and supercatalytic predictions. Clearly an improved understanding of catalytic properties for Mars entry conditions would greatly improve aeroheating prediction fidelity.

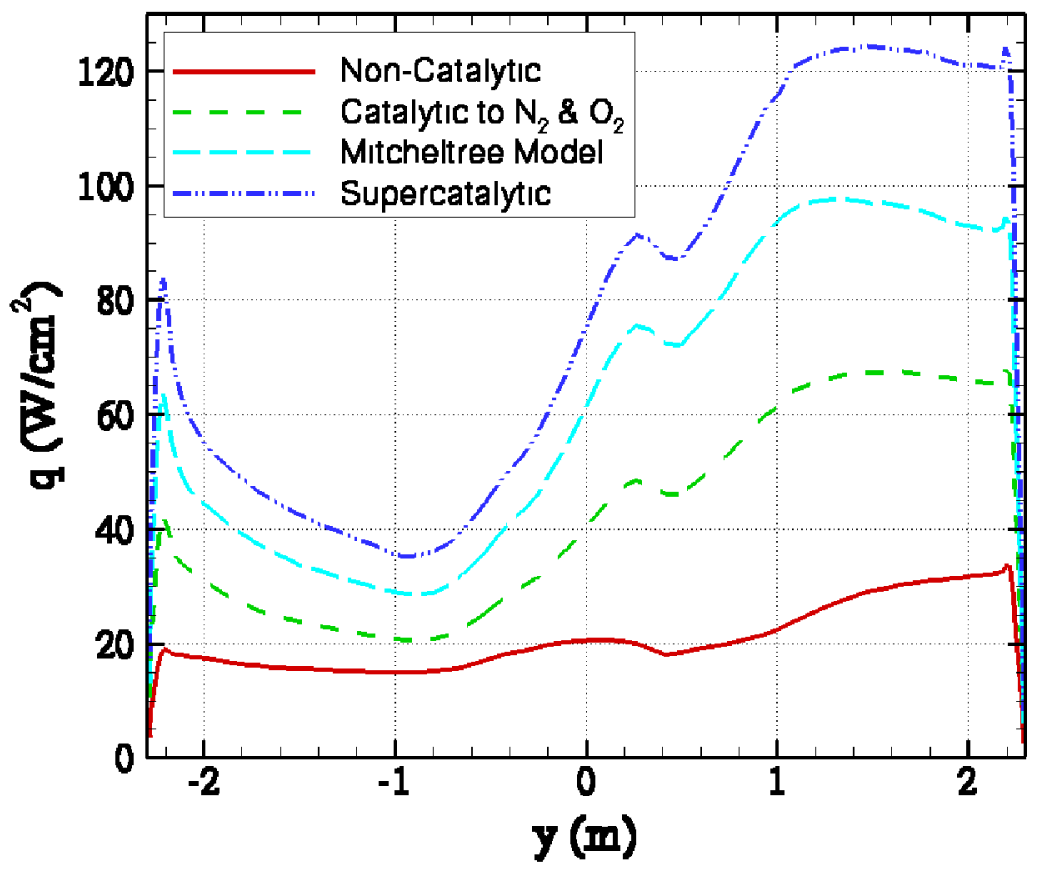

Figure 1. Effect of catalysis on predicted turbulent centerline heating for MSL.

In an attempt to bound the various catalytic models previously employed, Bose et al. ${ }^{80}$ recently developed a simple parametric model that includes two basic catalytic surface reactions:

$$
\begin{aligned}
& \mathrm{CO}+\mathrm{O} \rightarrow \mathrm{CO}_{2} \\
& \mathrm{O}+\mathrm{O} \rightarrow \mathrm{O}_{2}
\end{aligned}
$$

Recombination of $\mathrm{N}$ atoms is neglected because $\mathrm{N}_{2}$ is only a trace component of the Martian atmosphere, and remains mostly undissociated at entry velocities below about $7.5 \mathrm{~km} / \mathrm{s}$. However, $\mathrm{N}_{2}$ recombination could be readily added to the mechanism if necessary. No attempt is made to simulate the details of the surface kinetics or to determine whether the Eley-Rideal or Langmuir-Hinshelwood processes are occurring. Instead, the Bose et al. reaction mechanism ${ }^{80}$ is modeled using two free parameters: $\gamma_{c a t}$, which governs the total catalycity of the surface via either reaction R5 or R6, and $p_{2}$, which governs the preference of R6 over R5. Each of $\gamma_{c a t}$ and $p_{2}$ can vary independently from zero to one. Figure 2 shows the computed laminar stagnation point convective heat transfer as a function of $\gamma_{c a t}$ for the two limiting cases of $p_{2}=0$ and $p_{2}=1$. Inspection of Fig. 2 reveals a strong " $S$ " shaped curve in the catalytic heating as a function of $\gamma_{c a t}$. This shape appears because, as the catalycity changes, the mechanism gradually shifts from being limited by the diffusion rate of required reactants to the surface (large $\gamma_{c a t}$ ) to being limited by the rate of surface recombination reactions (small $\gamma_{c a t}$ ). Using this model, the Mitcheltree catalytic mechanism can be reproduced by setting $\gamma_{c a t}=1$ and $p_{2}=0$, while the homogeneous model can be reproduced 
(except the heating due to $\mathrm{N}$ recombination) by setting $\gamma_{c a t}=1$ and $p_{2}=1$, and the noncatalytic model is reproduced by setting $\gamma_{c a t}=0$. Note that this model was developed merely to parametrically bound the possible catalytic response of any thermal protection material in the hope that reaction specific data for relevant materials will be forthcoming in the future.

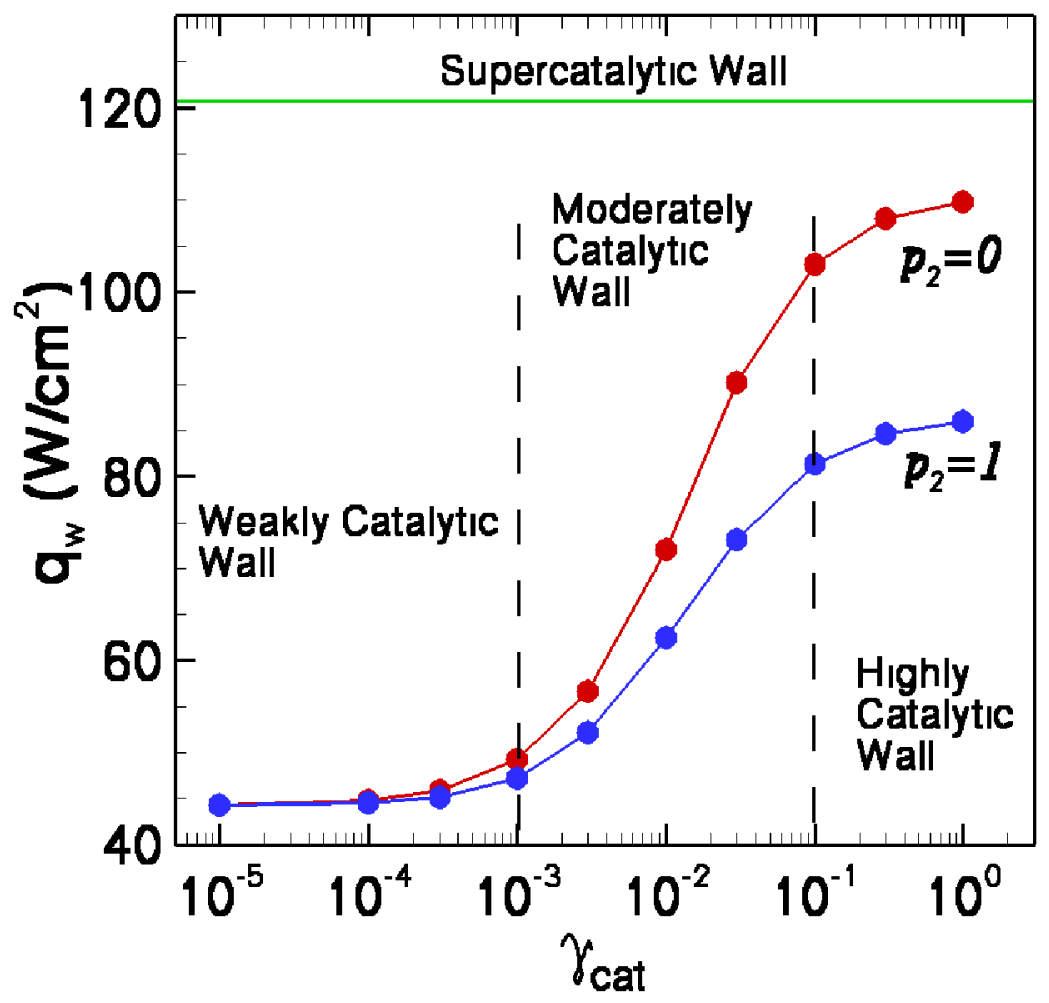

Figure 2. Stagnation point heat flux for Pathfinder as a function of catalysis model (Ref. 80).

Finally, it is important to note that in the above discussion it was assumed that the TPS material response (pyrolysis, glass melt and flow, vaporization, char formation, and recession) had no direct influence on the aeroheating environment and surface chemical kinetics. While this assumption is approximately valid for a nonablating or weakly ablating TPS, the environment for an ablating thermal protection material is much more complex and tightly coupled. As the material begins to char, pyrolize, and eventually ablate, hydrocarbons and other TPS material-dependent product species are injected into the flow. The char layer surface also reacts irreversibly with incident atoms in the boundary layer, leading to further mass injection. These ablation products influence the structure of the boundary layer, affecting the convective heating rate, both locally and potentially downstream as well. The exact nature of the species emitted is dependent on the specifics of the TPS material employed. Finally, as the TPS material begins to develop a surface char layer, the catalytic properties change, and the importance of catalytic reactions, which are now competing with oxidation, nitridation, sublimation and other reactions at the surface, may be diminished ${ }^{81-82}$ A true high-fidelity surface chemistry model should include the interaction between TPS material response and the aerothermal environment via a finite-rate coupled analysis. ${ }^{83}$ This type of analysis has not been performed to date for Mars entry conditions, mainly because the experimental data necessary to determine the rates of the required surface reactions is limited. However, significant advances have been made in the underlying numerical methods; ${ }^{145}$ these approaches should be tailored to Mars entry applications and the required physical data should be obtained.

\section{Transition and TURBulent HeAting}

Forebody transition was not a major concern on Viking (due to the low entry velocity), nor on MER (due to its small size). Transition was considered on Pathfinder, ${ }^{78}$ but it was not a major factor influencing the final design of the constant thickness TPS since no point on the body was predicted to have a fully turbulent heating level that exceed the laminar stagnation point heating. For the ballistic Phoenix entry vehicle turbulent flank heating was predicted to be slightly higher $(\sim 20 \%)$ than the stagnation point on some design trajectories; however, transition was 
not predicted to occur until well after peak heating. ${ }^{7}$ In contrast, the Mars Science Laboratory (formerly the Mars Smart Lander) is predicted to undergo turbulent transition on the forebody early in the trajectory due to the combination of large aeroshell size (4.5 meter diameter), high ballistic coefficient, and non-zero angle-of-attack ( $\alpha$ $16 \mathrm{deg}$ ). Early analysis in support of a potential 2005 launch predicted transition prior to peak heating ${ }^{40}$ using a smooth-wall momentum thickness Reynolds number based criterion $\left(\operatorname{Re}_{\theta}=200\right)$. While it was recognized that surface roughness and mass injection due to TPS ablation might promote earlier transition, ${ }^{42}$ these effects were not included in the analysis because even the best-case smooth-wall correlation predicted transition well before peak heating (see Fig. 3). More recent analysis using linear and parabolized stability theories also indicate the leeside flow is quite unsteady, primarily to first-mode disturbances, and is prone to early transition. ${ }^{46}$ From a design standpoint, if it is known that transition occurs prior to peak heating, the total integrated heat load (which determines TPS thickness) is not very sensitive to the precise time of transition. Therefore, it was deemed appropriate to assume a fully turbulent entry condition for sizing the TPS. At the time, the predicted peak unmargined smooth-wall turbulent heat flux on the leeward side of the forebody was about $65 \mathrm{~W} / \mathrm{cm}^{2}{ }^{40}$ At the time, a fixed uniform uncertainty of $50 \%$ was used, which would have resulted a design heat flux approaching $100 \mathrm{~W} / \mathrm{cm}^{2}$.

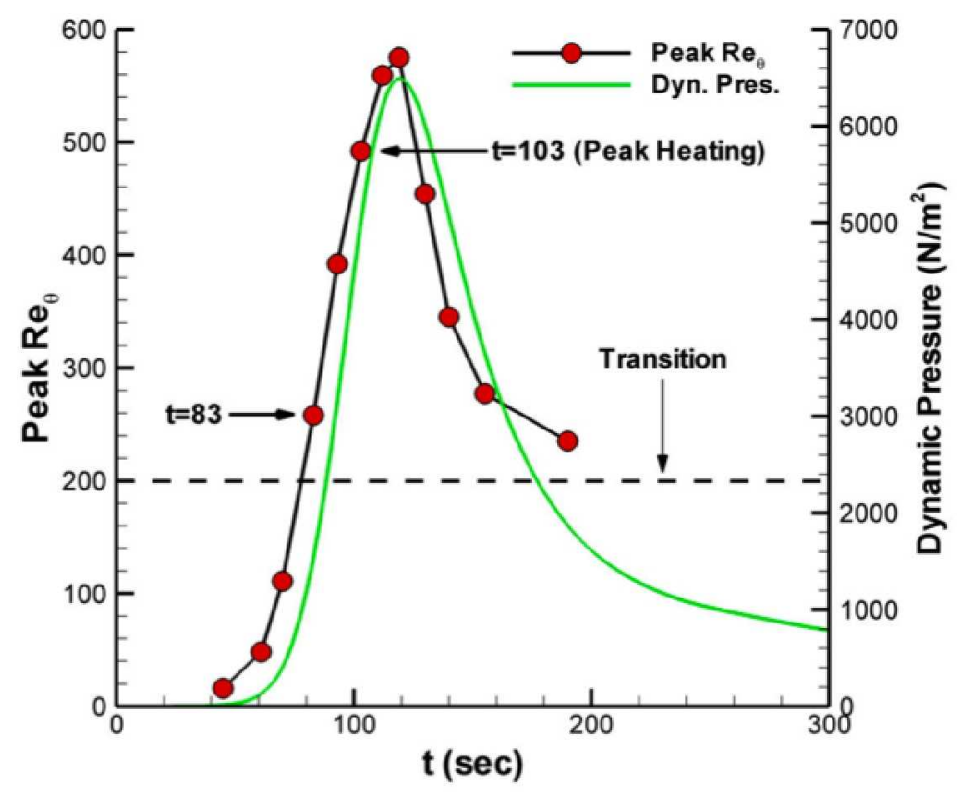

Figure 3. Predicted peak $\mathrm{Re}_{\theta}$ and dynamic pressure along 2005 MSL design trajectory (Ref. 40).

As the MSL design evolved to the current 2011 launch date, the peak predicted heating rate (including updated uncertainties) increased to about $190 \mathrm{~W} / \mathrm{cm}^{2}$ due to design and trajectory changes, as shown in Fig. 4 ( $V=$ $5.36 \mathrm{~km} / \mathrm{s}, \rho=8.205 \times 10^{-4}, T=161.6 \mathrm{~K}, \alpha=16.85^{\circ}$ ). Engineering estimates continued to indicate early transition to turbulence on the heatshield. Results from the Baldwin-Lomax and SST turbulence models were generally very similar over much of the aeroshell, although SST predicts somewhat (10-15\%) higher heating levels on the leeside, and lower (20\%) at the windside shoulder than the Baldwin-Lomax results (Fig. 4). The predicted turbulent heating rate on the leeside cone is now more than twice as high as that at the cone apex $(y=0)$. These results were surprising in that such large smooth-wall turbulent heating augmentation factors were not expected on the leeside of a blunt lifting sphere-cone geometry, although the experience base with blunt-body entry vehicles at high Reynolds numbers and angles-of-attack is admittedly limited. This effect is now understood to be due to entropy swallowing, ${ }^{84}$ and as such the forebody thermal protection system of the MSL mission must be sized according to the turbulent heat load and shear stress on the leeside of the forebody, rather than by those at the stagnation point. Unfortunately, until recently there has been little experimental (ground test or flight) data available to validate the computational predictions for this flow environment, which leads to large uncertainties in flight aeroheating predictions. For example, the MSL program is carrying a 50\% uncertainty on the predicted turbulent heating levels. ${ }^{77}$ An experimental program was followed for MSL that provided some of the data needed to anchor the CFD tools and understand the physics of turbulent transition and heating augmentation for 70 -deg sphere-cones. ${ }^{77}$ These tests (discussed further in Section 8 below) have demonstrated that the high turbulent heating rates predicted on the leeside of the cone are real and must be accounted for during the design of the TPS for the Mars Science Laboratory. 
In fact, these high heating rates, coupled to observed failures during arc jet testing of the planned TPS material (SLA-561V) led to a post Critical Design Review (CDR) change of TPS materials from SLA to the more aerothermally robust Phenolic Impregnated Carbon Ablator (PICA) material, which is applied as tiles. ${ }^{138}$ However, due to the significant differences between the ground test and flight environment, final validation of the turbulence models employed will not be possible until flight aeroheating data are obtained during a Mars entry.

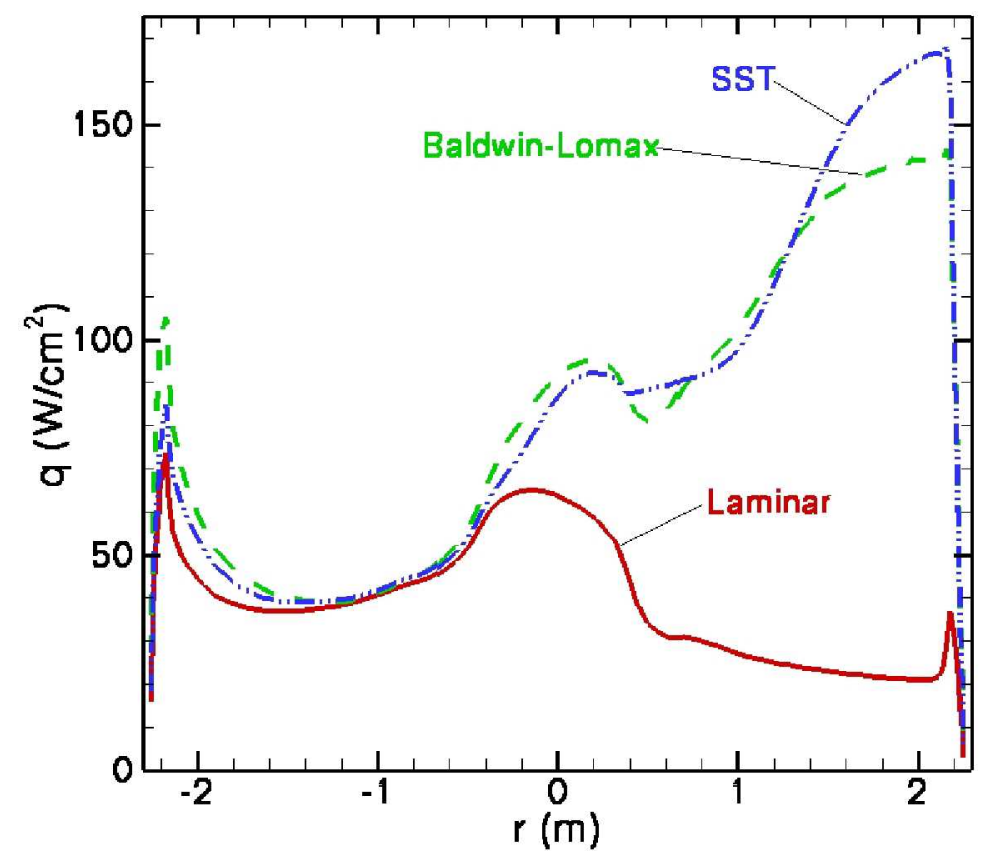

Figure 4. Predicted peak laminar and turbulent centerline heating for MSL along 2009 design trajectory.

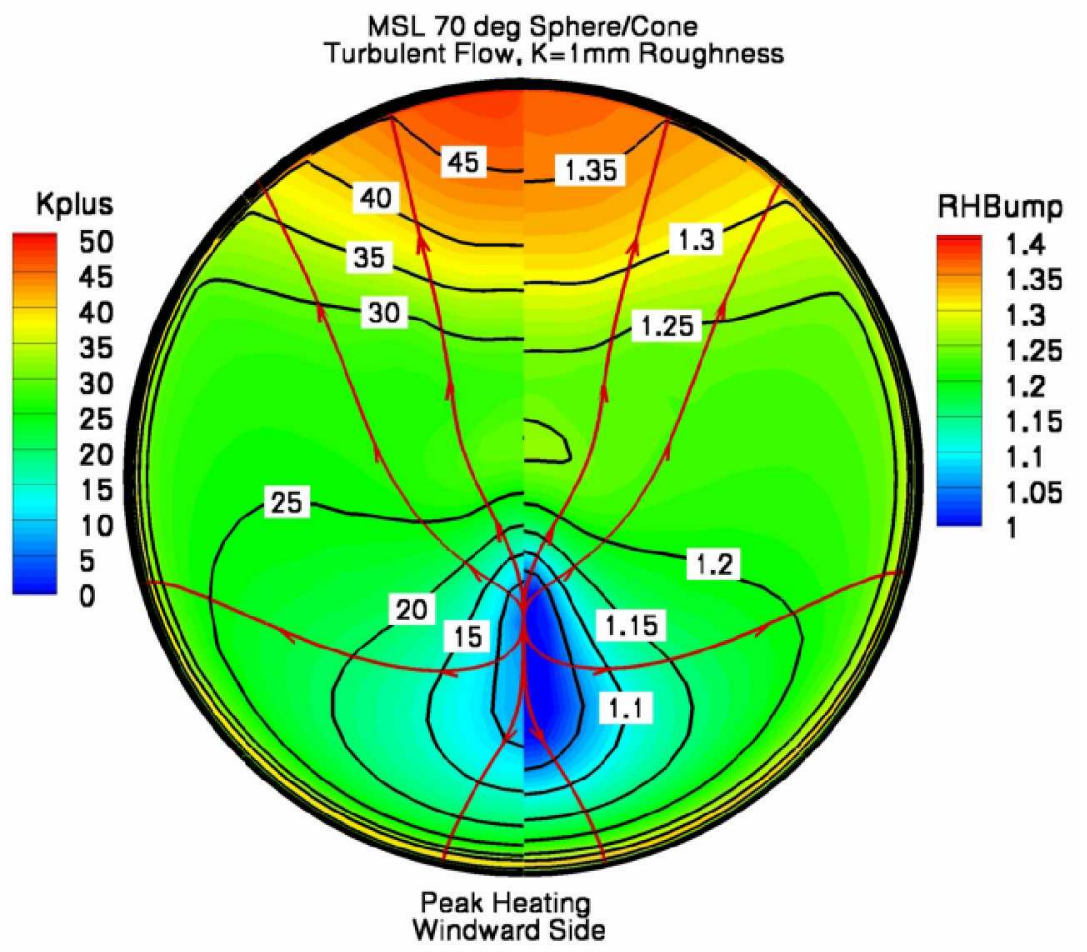

Figure 5. Computed $k+$ and turbulent heating augmentation factor on MSL aeroshell. 
Another area of concern for an ablating TPS is possible augmentation of the basic smooth wall turbulent heating level by ablation induced roughness. This effect was considered for previous blunt bodies, such as Apollo, but was not a major consideration because the peak heating rates occurred under relatively low shear stress conditions. However, for the MSL 70-degree sphere cone geometry, the peak heating and shear stress are approximately co-located on the leeside of the lifting heatshield due to entropy layer swallowing of the turbulent boundary layer. Figure 5 depicts the potential increase in turbulent heating due to ablation induced roughness on the MSL aeroshell at peak heating conditions for a previous 2010 design trajectory. The primary assumption in this analysis is that $1 \mathrm{~mm}$ pyramidal roughness elements are embedded in the acreage TPS material that produce an effective sand roughness of $k_{s}=1.24 \mathrm{~mm}$. The $1 \mathrm{~mm}$ roughness height was based on measurements of SLA-561V TPS samples ablated under laminar conditions in arc jets (this value was later reduced to $0.6 \mathrm{~mm}$ for the chosen PICA TPS material based on additional testing and analysis ${ }^{137}$ ). The high shear stress causes $k^{+}$to reach nearly 45 along the heat shield centerline giving a roughness heating bump factor of 1.35 at the location of peak heating using Eqs. (2) and (3). This heating augmentation would likely be partially mitigated by blowing of the pyrolysis products, which will thicken the laminar sublayer, thus decreasing $k^{+}$for a given roughness height. Roughness will not have a significant impact on afterbody heating due to the low shear stresses (and correspondingly low $k^{+}$) encountered in this region.

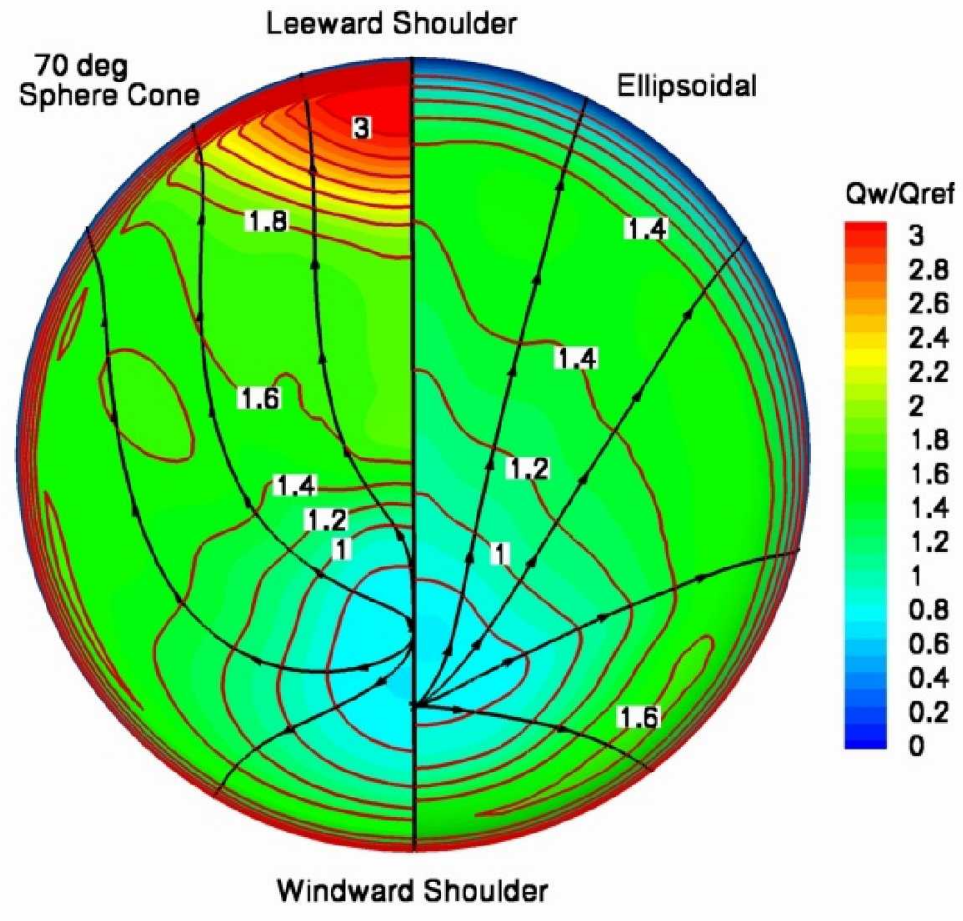

Figure 6. Predicted peak turbulent heating for a $70^{\circ}$ sphere cone and equivalent ellipsoidal aeroshell.

Brown ${ }^{84}$ has shown via real gas CFD simulations that the observed high turbulent heating level on the leeside of a lifting 70-deg sphere-cone is due to an entropy swallowing effect caused by the proximity of the real-gas shock to the boundary layer along the leeside cone surface just downstream of the strong expansion around the nose. Brown also demonstrated that an ellipsoidal aeroshell, with the same predicted hypersonic aerodynamic performance as the baseline 70-deg sphere-cone, avoided this effect, resulting in a 50\% reduction in peak heating rate and a $67 \%$ reduction in zero margin TPS mass for a conceptual Mars aerocapture design. ${ }^{85}$ An example of the computed heat transfer for the aerocapture concept ${ }^{85}$ is shown in Fig. $6\left(V=6.49 \mathrm{~km} / \mathrm{s}, \rho=6.50 \times 10^{-4}, \alpha=16^{\circ}\right)$. The left side of the image shows turbulent heating assuming a "heritage" 70-deg sphere-cone geometry, while the right side shows computed heating for the same freestream conditions for an ellipsoidal aeroshell with nearly identical hypersonic aerodynamics. The heating rate in Fig. 6 has been normalized by the stagnation point heating to clearly show the heating augmentation factors. As shown in Fig. 6, the 70-deg sphere-cone shows a leeside augmentation of about 3.0, while the ellipsoidal aeroshell shows a peak augmentation of only 1.4. In addition, the ellipsoidal aeroshell exhibits much smaller gradients and lower peaks in the computed heat flux and shear stress along the 
shoulder of the heatshield. A full shape optimization study was not performed, but nevertheless this work indicates the potential that significant savings in TPS mass may be obtainable by going away from the traditional 70-deg sphere-cone shape for future MSL-class Mars entry vehicles. In fact, preliminary analysis of the heating produced on an ellipsoidal aeroshell flying at MSL conditions indicates that the reduction in predicted heating rates might have been sufficient to use the heritage SLA-561V material for this application. These computational results are currently being checked via ground testing in the CalTech T5 shock tunnel facility, and a future paper will present comparisons between CFD predictions and experimental results. The original choice of a $70^{\circ}$ sphere-cone for Viking was motivated by the desire to maximize drag during entry, and was appropriate for entry from orbit where transition to turbulence was not predicted. ${ }^{151}$ However, subsequent use of this design, without a full understanding of its potential limitations for larger, higher ballistic coefficient entry bodies, has demonstrated the dangers inherent in overreliance on extrapolations of heritage.

\section{Afterbody Heating}

Uncertainty levels associated with aeroheating predictions for the design of the afterbody of Mars entry probes are much larger than those on the forebody. For example, the MSL program is carrying a $200 \%$ uncertainty on the predicted acreage laminar afterbody aeroheating predictions. ${ }^{77}$ These large uncertainties can have a significant impact on TPS material selection and total backshell mass. This potential conservatism in the afterbody heat shield design will also shift the center of gravity aftward, which reduces static stability and in some circumstances may necessitate the addition of ballast in the nose. A primary reason for the large uncertainty in afterbody heating predictions is a scarcity of relevant data for validation of the computational tools. Little flight data exist, particularly for Mars entry conditions (see Section 9). A recent review paper ${ }^{86}$ summarized available sources of afterbody flight data for Earth and planetary entry missions as well as published attempts to reproduce these data with modern CFD. Ground test data can be helpful, but are usually complicated by sting interference effects ${ }^{87-88}$ and extrapolation to flight conditions. Free-flight facilities, such as ballistic ranges, can theoretically provide a suitable quiescent flow base heating environment. These facilities have not traditionally been employed for quantitative aerothermal testing, although new developmental infrared optical techniques show some promise. ${ }^{89}$

On the computational side, afterbody calculations are far more complex and time consuming than forebody only simulations, because of the presence of a large separated vortical flow, which converges slowly and requires highly refined feature-aligned computational grids to fully resolve the necessary length scales. Until recently even axisymmetric afterbody calculations taxed the capabilities of existing computers and CFD algorithms. However, recent advances, including robust highly parallelizable implicit algorithms and the advent of low-cost distributed memory "commodity" computer clusters, has made the computation of full 3D wake flows tractable. Recent results for flight missions are briefly reviewed in this section.

Base heating predictions for the Mars Pathfinder entry vehicle were made by Mitcheltree and Gnoffo ${ }^{24}$ and Haas and Venkatapathy. ${ }^{90}$ These calculations were some of the first applications of modern nonequilibrium reacting flow Navier-Stokes CFD analysis for design predictions of afterbody heating for a planetary entry spacecraft. Mitcheltree and Gnoffo performed axisymmetric calculations at the peak heating and peak dynamic pressure points on the design trajectory. Their results predicted a peak laminar afterbody heating of about $7 \mathrm{~W} / \mathrm{cm}^{2}$, or about $6 \%$ of the peak forebody heating rate. ${ }^{24}$ The maximum heating rate was observed to occur at the rear stagnation point on the flat base, and the value was predicted to be about the same at both trajectory points. Haas and Venkatapathy ${ }^{90}$ performed similar computations at four points along the trajectory. They observed a maximum laminar afterbody heating rate of $8 \mathrm{~W} / \mathrm{cm}^{2}$, which occurred at the same time as peak forebody heating. None of these calculations included the effects of turbulence, which was carried as an uncertainty factor in the final TPS design.

Turbulent afterbody heating was initially a concern during the design of the MER backshell. Flight data from the Viking aftshell showed that the ratio of peak backshell to forebody stagnation point heating abruptly increased as the diameter-based freestream Reynolds number increased to about $500,000 .{ }^{91}$ This trend was originally interpreted as transition to turbulence, which if true implied that afterbody transition would be an issue for MER as well. However, during the MER TPS design it was determined that this effect was reproducible using purely laminar CFD simulations (Fig. 7), and was actually due to the fact that peak afterbody heating occurs later in the trajectory than peak forebody heating (typically around the time of peak forebody stagnation pressure). This time delay leads to a slope change in the ratio of stagnation point to backshell heating rate as a function of time (or Reynolds number) at the point where heating on the forebody begins to fall while backshell heating continues to increase. In large part due to this finding, the MER program elected to design to a fully laminar backshell heating environment. 


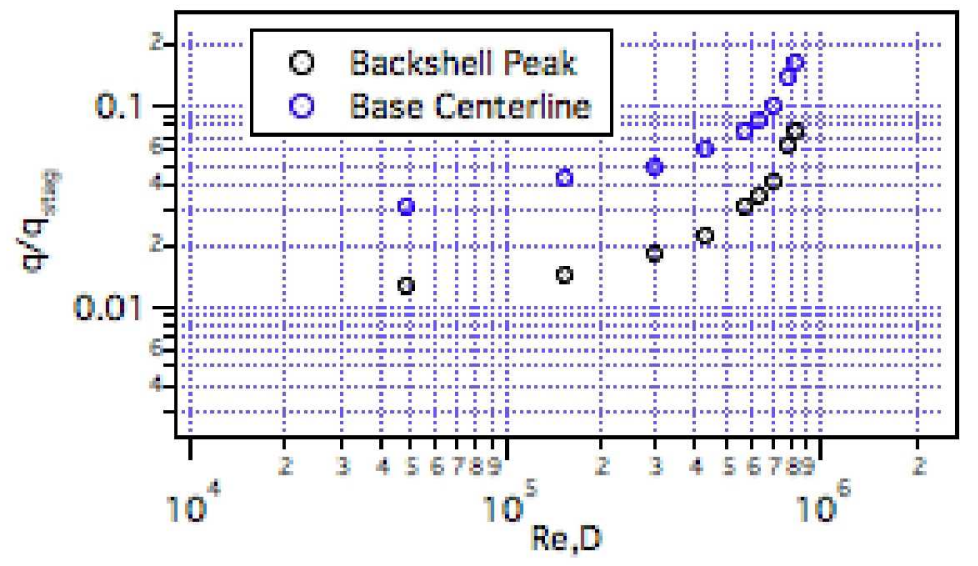

Figure 7. Computed backshell heating for MER as a function of freestream Reynolds number.

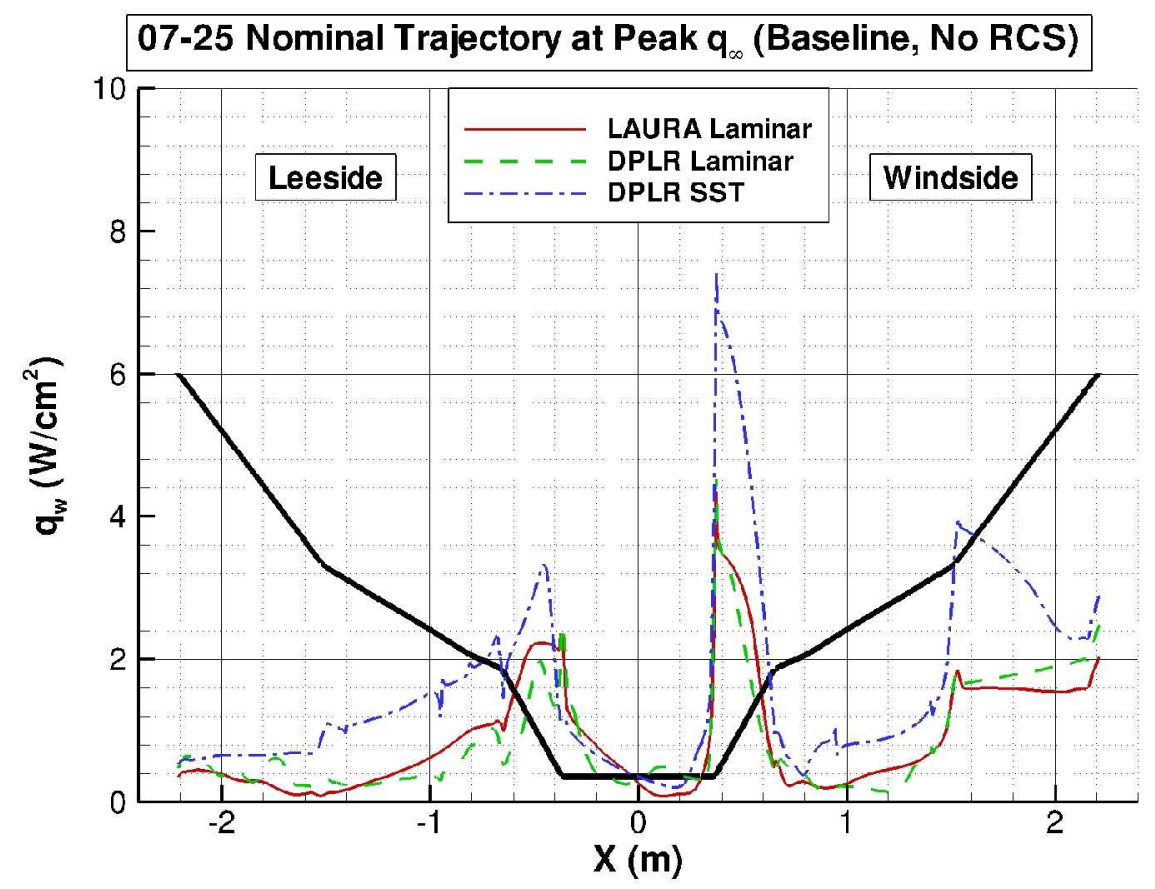

Figure 8. Normalized MSL afterbody symmetry plane heating rates (Ref. 133).

More recently, Morabito and Edquist ${ }^{92}$ simulated the afterbody heating of the MSL vehicle at angle of attack. These calculations are the first published design analyses of a three-dimensional Mars entry body base flow. Morabito and Edquist ${ }^{92}$ used an ionized flow Mars kinetic model to simulate electron number density in the wake for the purpose of estimating radio blackout times during entry in several proposed communication bands. The predicted wake electron number density was estimated to be accurate only to within an order of magnitude, due to uncertainties in wake flow modeling and the basic kinetic rates. The results indicated that blackout of up to 95 seconds is possible during hypersonic entry for communications in the UHF band, while the blackout time in the Xband is much shorter. Later, Edquist et al. ${ }^{77,93,133}$ reexamined the base region, this time looking at acreage and detail aeroheating effects as well as definition of design uncertainties. Edquist et al. ${ }^{133}$ predicted that afterbody heating rates are generally below $3 \%$ of the forebody laminar nose cap heating rate, with the maximum normalized value occurring near the time of peak freestream dynamic pressure (Fig. 8). The maximum heat flux occurs on the windside lip of the parachute closeout cone, where the shear layer from the separated flow impinges on the surface. A local maximum also occurs on the first afterbody cone on the windward side at an angle of attack of $16 \mathrm{deg}$, where the flow remains attached. These simulations were performed assuming laminar flow due to concerns about the validity of available turbulence models discussed previously. MSL carries an afterbody heating environments 
uncertainty of $200 \%$ to represent the difficulty in computing wake flowfields and estimated effects of turbulent transition. ${ }^{133}$ This uncertainty level more than encompasses the predicted difference between laminar and turbulent (SST) flow on the backshell. Edquist et al. ${ }^{133}$ also explored the effects of Reaction Control System (RCS) interference heating on the backshell; these results will be summarized in Section. 7. Comparisons of CFD and Viking afterbody temperature data were performed recently in an attempt to better quantify afterbody heating uncertainties; ${ }^{94}$ the results are summarized in Section 9.

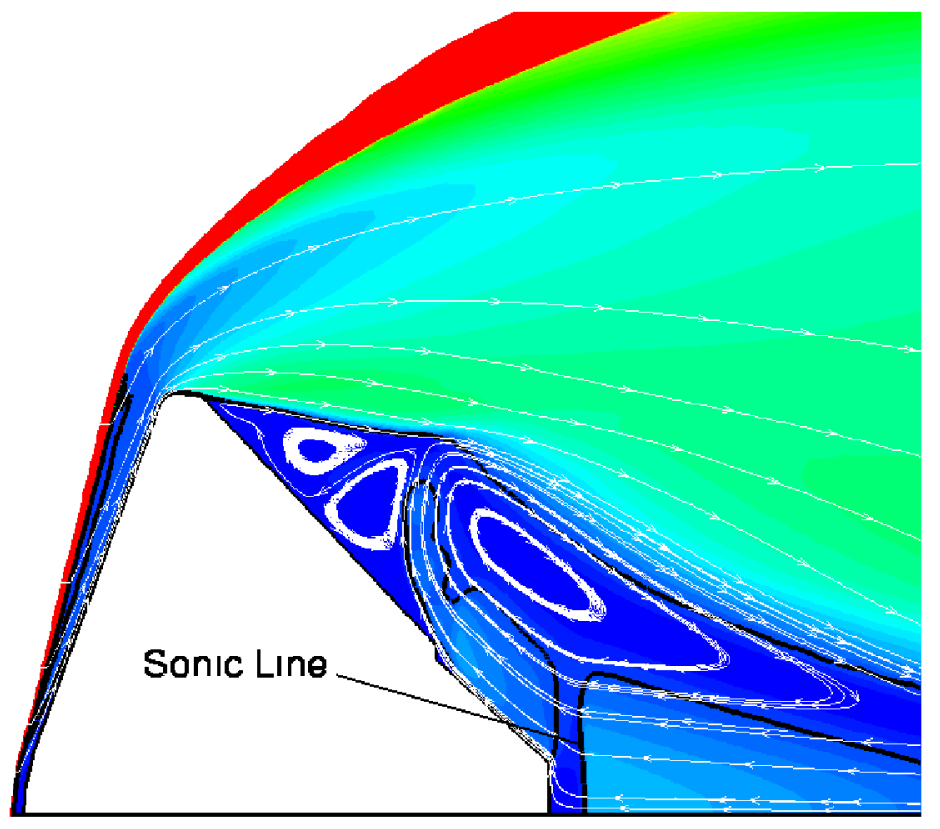

Figure 9. Computed Phoenix afterbody streamlines and Mach contours.

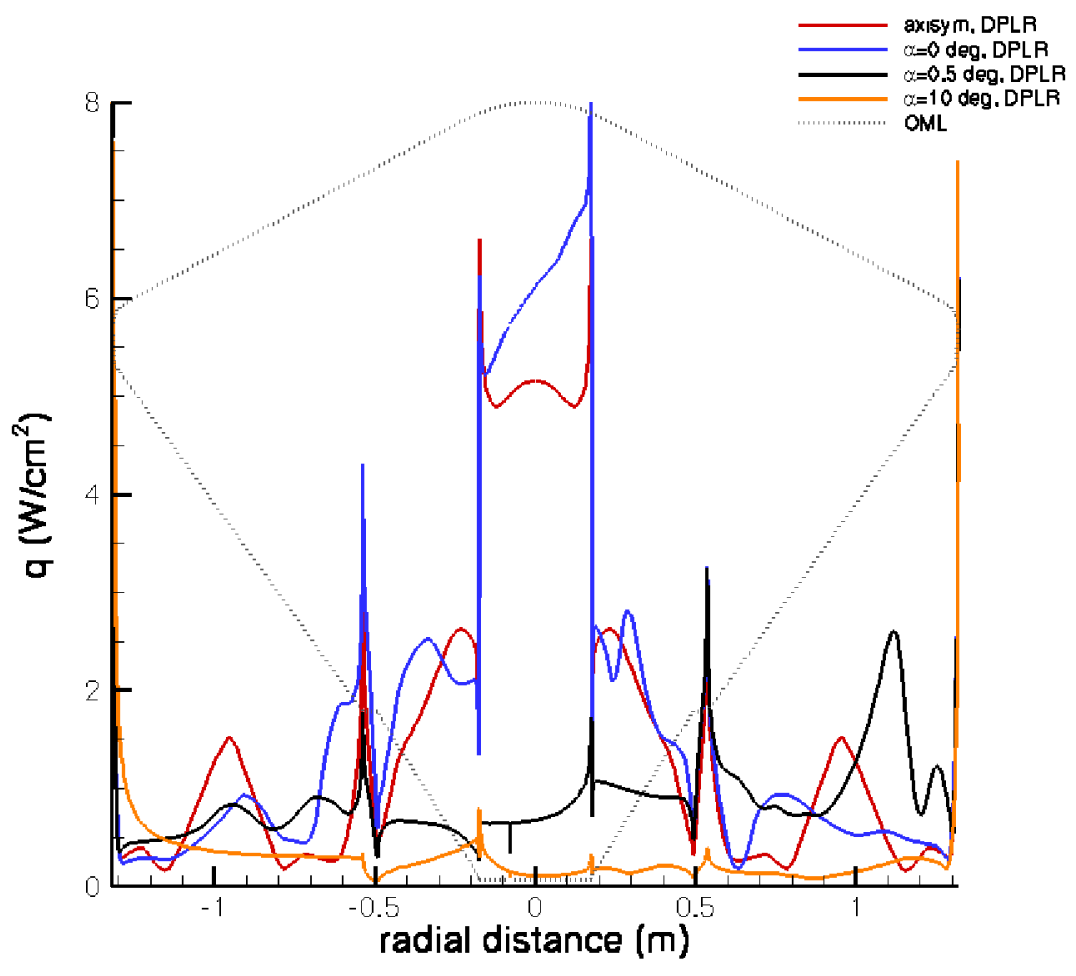

Figure 10. Phoenix afterbody heating rate as a function of angle of attack (adapted from [7]). 
Mars Phoenix afterbody heating calculations were performed by McDaniel et al. ${ }^{7}$ Although Phoenix was launched four years prior to MSL, full three-dimensional CFD calculations were not performed until much later in the program. The baseline aftshell TPS design was based on axisymmetric CFD simulations of the ballistic entry, but after the preliminary design review a limited number of three-dimensional calculations were desired to bound the design environment $\left(\alpha<10^{\circ}\right)$. Figure 9 shows the wake region of the Phoenix vehicle $(V=5.103 \mathrm{~km} / \mathrm{s}, \rho=$ $4.0 \times 10^{-4} \mathrm{~kg} / \mathrm{m}^{3}, T=147.9 \mathrm{~K}$ ) as computed assuming an axisymmetric flowfield. Streamlines and Mach number contours are plotted which highlight the complex wake structure. The sonic $\left(M_{a}=1\right)$ line is also shown. As can be seen in Fig. 9 there is a region along the rear stagnation line where the reverse flow becomes supersonic. In order for this flow to stagnate on the base a disk shock is formed, which results in a high heating rate at the rear stagnation point. As shown in Fig. 10, the resulting peak heating rates were about $4.5 \mathrm{~W} / \mathrm{cm}^{2}$ at the rear stagnation point and 7 $\mathrm{W} / \mathrm{cm}^{2}$ at the parachute cone corner. ${ }^{7}$ Three-dimensional simulations run at zero degrees angle of attack still contained the disk shock, but the overall flowfield became slightly non-symmetric. This asymmetry was attributed to the inherent unsteadiness of separated base flows; simulations on a full three-dimensional grid allowed for excitation of the 3D unsteadiness modes that were artificially suppressed in axisymmetric calculations. Finally, simulations at angle of attack ${ }^{7}$ showed that this disk shock disappeared, the extent of the separated flow region shrunk, and the resulting heating rates on the entire separated flow portion of the backshell dropped considerably for $\alpha>0.5^{\circ}$. Similar trends have been observed by multiple researchers in previous entry vehicle designs. In fact, the design environments for Mars Pathfinder, ${ }^{24}$ MER, and Stardust ${ }^{95}$ were also governed by disk-shock augmented heating at the rear stagnation point. At this time it is not known whether this disk shock is a numerical artifact or a real physical phenomenon. However, it should be noted that no experimental evidence of the existence of a disk shock in a hypersonic base flow has been discovered by the authors.

\section{SHOCK LAYER RAdiation}

In general, the shock layer during Martian entry will be in thermochemical nonequilibrium during the hypersonic portion of the trajectory. In such a shock layer, the amount of radiation generated is governed by finiterate processes including excitation of atoms and molecules via collisions, spontaneous or stimulated emission of photons from the excited states, and absorption of photons by other species in the shock layer. The resulting radiation spectrum is extremely non-blackbody, and is in fact dominated by strong spectral features corresponding to atomic lines and molecular bands. A true non-equilibrium radiation model must include models for all of these processes, as well as for the transport of radiation through the shock layer to the body surface. The principle radiators in a weakly ionized $\mathrm{CO}_{2}-\mathrm{N}_{2}$ shock layer are the $\mathrm{CO}(4+)$ molecular band system, which radiates in the near ultraviolet (UV); the $\mathrm{CN}[\mathrm{B}-\mathrm{X}]$ and $[\mathrm{A}-\mathrm{X}]$ band systems, which radiate in the violet and red respectively; the $\mathrm{C}_{2}$ Swan band, which radiates in the blue-violet region, and atomic radiation, primarily from $\mathrm{C}$ and $\mathrm{O}$ atoms, which contribute some radiation in the UV, visible, and infrared (IR) portions of the spectrum. Finally, continuum radiation from bound-free and free-free transitions can become important for high entry speeds that produce ionized flow fields. Molecular radiation from $\mathrm{CO}_{2}$ is not an important contributor at high speeds because the carbon dioxide is completely dissociated in the shock layer before becoming hot enough to radiate significantly. However, IR radiation from $\mathrm{CO}_{2}$ vibrational transitions may be important at lower entry velocities, or later in the entry when the vehicle has decelerated to velocities low enough $(9<\mathrm{M}<16)$ to excite, but not dissociate, the $\mathrm{CO}_{2}$. This $\mathrm{IR}$ vibrational radiation component has not been considered previously for NASA Mars entry vehicles, but may play a role in the design of new, larger entry systems, particularly for those cases where the vehicle enters from orbit. Figure 11 shows the predicted spectrum from 1000-5000 $\AA$ for the simulated entry of a Pathfinder class vehicle at $8.5 \mathrm{~km} / \mathrm{s}$. The calculation was done assuming a Boltzmann distribution of all excited state species at the mixture vibrational temperature. As can be seen, the dominant radiator is the CO (4+) system between 1000-2000 $\AA$. Two strong carbon atom emission lines are also visible, as is the $\mathrm{CN}$ violet system, peaking at $3800 \AA$.

Existing Mars radiation models generally assume that the excited states of the relevant species maintain a Boltzmann distribution at the mixture electronic temperature (typically assumed to be equal to the vibrational temperature - see Section 2). A review paper by Park et al. ${ }^{18}$ presented Boltzmann radiation calculations for a viscous non-equilibrium shock layer. The results neglected the non-adiabatic radiative cooling effect, which will reduce the radiative heat transfer since the radiative emission reduces the shock layer temperature. However, this effect is thought to be small in the nonequilibrium regime except at very high entry velocities. The Park et al. ${ }^{18}$ results predict stagnation point radiative heating levels from $19 \mathrm{~W} / \mathrm{cm}^{2}$ for a sphere of $1 \mathrm{~m}$ radius at an entry velocity of $7 \mathrm{~km} / \mathrm{s}$ to $190 \mathrm{~W} / \mathrm{cm}^{2}$ for a sphere of $10 \mathrm{~m}$ radius at an entry velocity of $9 \mathrm{~km} / \mathrm{s}$. Hartung et al. ${ }^{96}$ and Tauber and Sutton ${ }^{97}$ previously published computational results for Mars shock layer radiation assuming an inviscid shock layer in thermochemical equilibrium. The inviscid equilibrium results are generally lower than the viscous nonequilibrium 
results due to the nonequilibrium overshoot phenomenon. Non-Boltzmann air radiation models have been developed for moderate entry velocities. ${ }^{98}$ These models have been shown to be in reasonable agreement with available flight data from the Fire-II flight test, ${ }^{99}$ and predict much lower heating levels than those predicted using a Boltzmann assumption. Unfortunately, no such flight-validated models exist for Martian entries. However, recently several shock tube studies have been undertaken in pure $\mathrm{CO}$ and $\mathrm{Ar}: \mathrm{CO}_{2}: \mathrm{N}_{2}$ mixtures. ${ }^{100-103}$ Zalogin et al., ${ }^{102}$ has developed a preliminary collisional-radiative gas-kinetic model for radiation prediction. Additional ground based data at pressures low enough to show significant nonequilibrium, such as that obtained recently for CN radiation, ${ }^{104}$ would be of great benefit to validate the proposed models for aerothermal design. However the experimental techniques are much more complex than those for Titan radiation, because the principle radiator (CO) emits in the ultraviolet (Fig. 11), which is strongly absorbed in ambient air. Therefore the entire light path of all instruments must be evacuated during testing, and special UV-transparent windows and optics must be employed. Most previous shock tube studies concentrated on the much weaker $\mathrm{CN}$ violet radiation signature because of the difficulties in obtaining calibrated $\mathrm{CO}(4+)$ data. Testing is currently underway in the NASA Ames EAST shock tube facility during 2009-2010 that will provide a valuable additional source of $\mathrm{CO}_{2}$ shock layer radiation data, ${ }^{146}$ and spectroscopic constants for some of the key radiating species are being updated via $a b$ initio methods. ${ }^{142}$

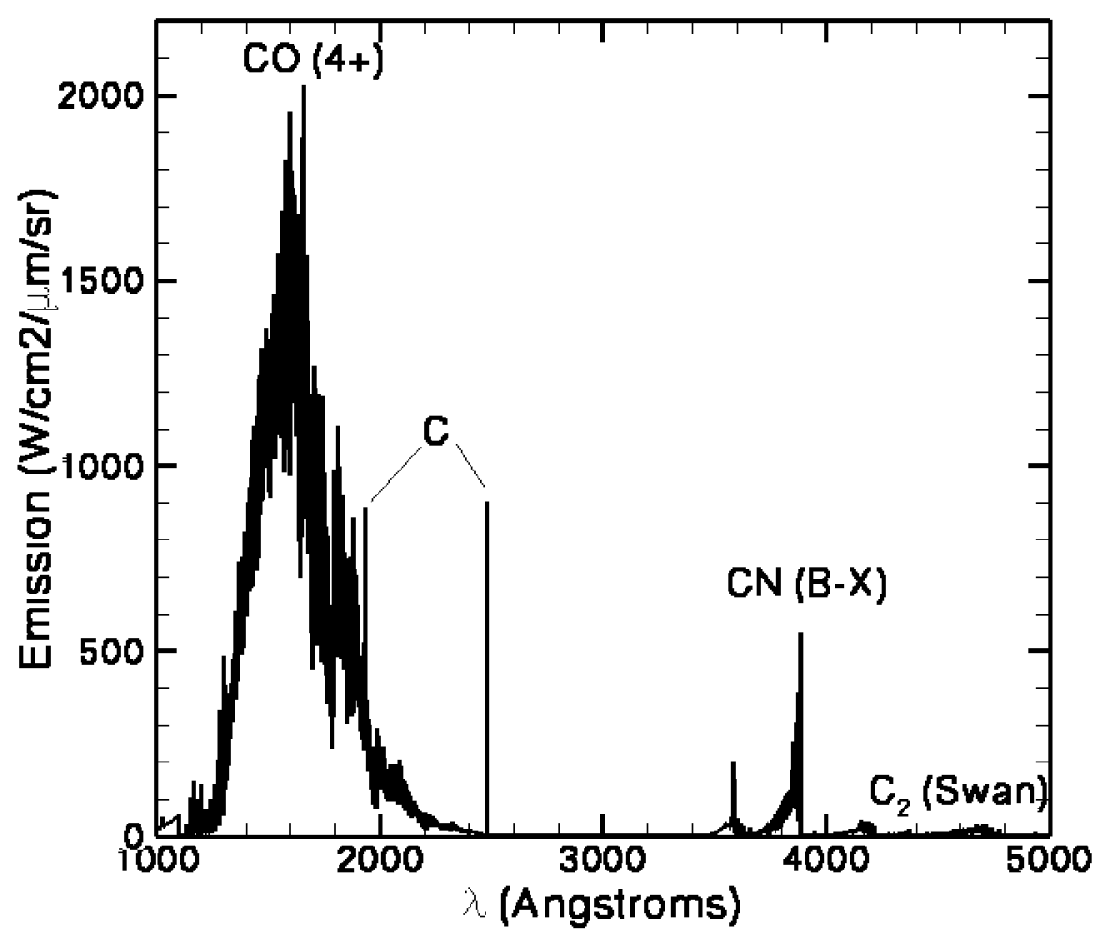

Figure 11. Simulated Mars shock layer radiation spectrum at 8.5 km/s.

The only Mars entry mission to date for which shock layer radiation was predicted to be significant was Mars Pathfinder. The Pathfinder probe was a $70^{\circ}$ half-angle sphere-cone with a nose radius of $0.66 \mathrm{~m}$ and a diameter of $2.65 \mathrm{~m}$. The entry velocity was $7.5 \mathrm{~km} / \mathrm{s}$. Pre-flight predictions of the peak radiative heating for Pathfinder ranged from about 5-12 W/cm ${ }^{2}$ (Refs. 10,24) compared to a predicted convective heating rate of $115 \mathrm{~W} / \mathrm{cm}^{2}$ and a total heating rate inferred from in situ temperature measurements of about $100 \mathrm{~W} / \mathrm{cm}^{2}{ }^{105}$ Current estimates for the MSL mission indicate that less than $0.1 \mathrm{~W} / \mathrm{cm}^{2}$ of radiative heating will occur (not including a yet to be evaluated component from $\mathrm{CO}_{2}$ vibrational transitions). However, future missions, particularly crewed entry vehicles and precursor cargo missions, may experience significant amounts of radiative heating, due to a combination of large size and high entry velocity.

\section{SingulaRity HeATING}

The previous sections of this review have all dealt with acreage heating effects. However, localized heating in the neighborhood of heatshield penetrations or backshell singularities, as well as transient interference heating due to RCS thruster impingement, must also be considered in the design of the overall TPS. Prior to MER, localized 
heating effects were typically accounted for with engineering-based "bump factors" which attempted to bound the expected local heating augmentation due to the presence of the singularity. Such engineering level analyses were necessary due to the high computational cost of full-body CFD simulations at that time.

Late in the design of the MER aeroshell, three Transverse Impulse Rocket System (TIRS) motors were added to the backshell, intended to minimize lateral velocity during the parachute descent and terminal landing phases. Because these TIRS motors protruded through the backshell, TPS covers were required to protect the motors from the entry environment. These covers were designed to be jettisoned before the TIRS became active on terminal descent. Aerothermal heating predictions were made on the TIRS using full-body three-dimensional CFD analysis. ${ }^{106}$ These calculations predicted a margined maximum local heat flux to the cover of $7.5 \mathrm{~W} / \mathrm{cm}^{2}$. The highest heating rate occurs on the aft end of the TIRS cover due to the large recirculation region on the backshell. Final sizing for the TIRS cover TPS was based on these analyses and included margins to account for uncertainties arising from transition to turbulence and aerothermal environment variations. The design of the protective cover and its interface with the backshell were then validated through arc jet testing, ${ }^{106}$ and the covers performed successfully during both MER entries. Unfortunately, since the MER aeroshell was not instrumented, it is not possible to validate the design of these singularities any further.

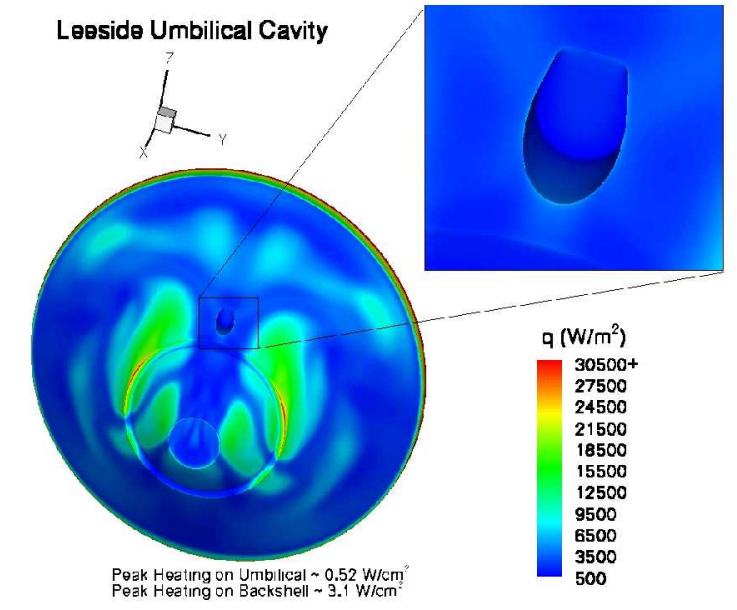

a) b)

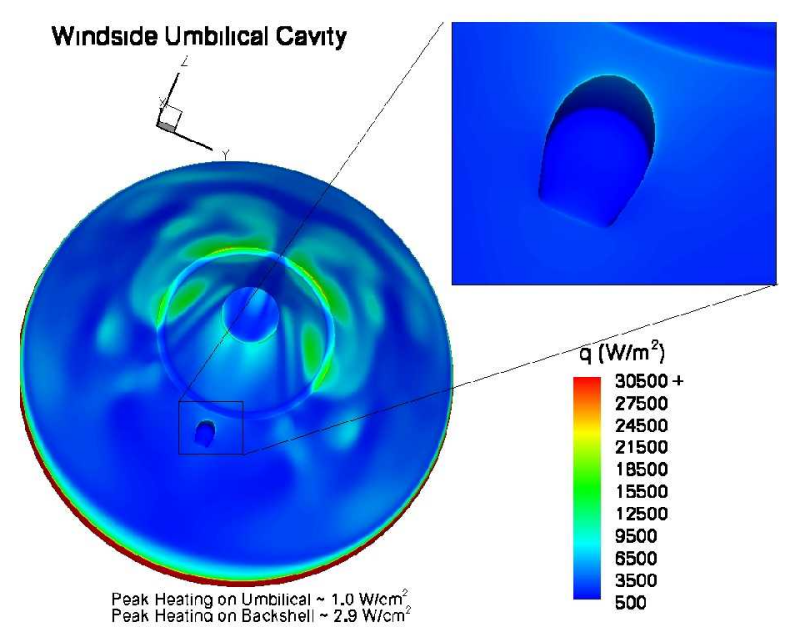

Figure 12. Computed Phoenix backshell heat transfer showing umbilical cavity heating: a) leeside, and b) windside (Ref. 7).

The aftshell of the Phoenix entry vehicle includes several singularities and penetrations, including vents, RCS thrusters, and umbilical wells. While previous Mars missions relied in large safety factors on the baseline smooth wall environments to account for possible local augmentation, the two large umbilical wells on the Phoenix aftshell were deemed worthy of additional analysis for this mission. McDaniel et al. ${ }^{7}$ computed a total of two CFD solutions in order to examine the local heating around the umbilical cavity; one for each of the leeward and windward orientations at the peak pressure point on the maximum heat rate design trajectory. The cases were run at the design limit angle of attack $\left(\alpha=10^{\circ}\right)$. The flowfield for both cases was slightly unsteady, with heating levels varying about $\pm 15 \%$ in the cavity region due to vortical motion in the cavity well. Figure 12 shows representative computed radiative equilibrium surface heating on the backshell for the two cases. As seen in the figures, the peak heating rate on the aftshell $\left(\sim 3.1 \mathrm{~W} / \mathrm{cm}^{2}\right)$ occurs on the rearward facing step on the parachute cover. The heating in the vicinity of the umbilical cavity is much lower, with a peak value of only $0.5-1.0 \mathrm{~W} / \mathrm{cm}^{2}{ }^{7}$ Although both umbilical cavities create significant disturbances to the afterbody flow, neither singularity appears to be a major concern from a TPS design standpoint. In both cases the highest local heating occurs on the downstream lip where the flow is turned parallel to the backshell surface after stagnating on the rear wall of the cavity. However, the highest localized heating is only about a third of the peak observed on the parachute cover. Given that the entire backshell is designed with a constant thickness TPS, the baseline design should be more than sufficient to protect against localized heating around the umbilical cavities.

Singularity analysis for the MSL backshell focused on the localized heating produced by the protruding antennae on the parachute closeout cone (PCC). CFD was performed for several of these protrusions by Edquist et al. ${ }^{133}$ and the resulting computed heating augmentation factors were used in the sizing of the Acusil-II TPS on the PCC. Results were obtained with two codes. While both codes showed augmented heating on the upstream 
(attachment) side of the protrusions, there were significant differences between the codes in both predicted magnitude and extent of augmentation. However, it should be noted that many simplifications were made in the analysis for both Phoenix and MSL. First, results were obtained at only a few trajectory points. In addition, the flowfield was assumed to be entirely laminar, and unsteady effects were neglected. Finally, no rigorous validation has been done to date of the ability of real gas Navier-Stokes codes to predict local heating around singularities in separated flows, particularly in high enthalpy $\mathrm{CO}_{2}$ environments. These and other uncertainties contributed to the large design margins placed on aerothermal predictions of the local heating environments used for design.

In addition, when the MSL program switched from SLA-561V to the tiled PICA heatshield design, an additional potential singularity heating source was introduced in the form of gap-filler protrusion. The gap-filler (RTV-560) used between the PICA tiles was shown in arc jet testing to be more resistant to oxidation induced recession than the acreage TPS. ${ }^{138}$ Therefore, as the PICA material receded in flight, it is possible that the gap filler may protrude above the surface, creating locally augmented heating due to discrete (as opposed to distributed) roughness elements. Tang et al. ${ }^{140}$ performed numerical simulations (Fig. 13) of worst-case protrusions in both flight and arc jet environments, and demonstrated local augmentation factors in fully turbulent flow of up to 3 . The region of highest heating augmentation was typically immediately downstream of the edge of an isolated gap-filler positioned obliquely with respect to oncoming streamlines. This effect, attributed to vortical flow generated in the wake of the gap filler edge, created high local augmentation that was determined not to significantly impact design, because the TPS material would laterally conduct away much of the augmented heating. Larger regions of the heatshield experienced bump factors that increased with increasing gap-filler height, with an apparent asymptotic maximum of about two times the smooth wall heating. Fortunately the PICA heatshield was designed with large margins, and it was shown that the resulting design would be sufficiently robust to cover the worst-case predicted augmentation factors. ${ }^{141}$

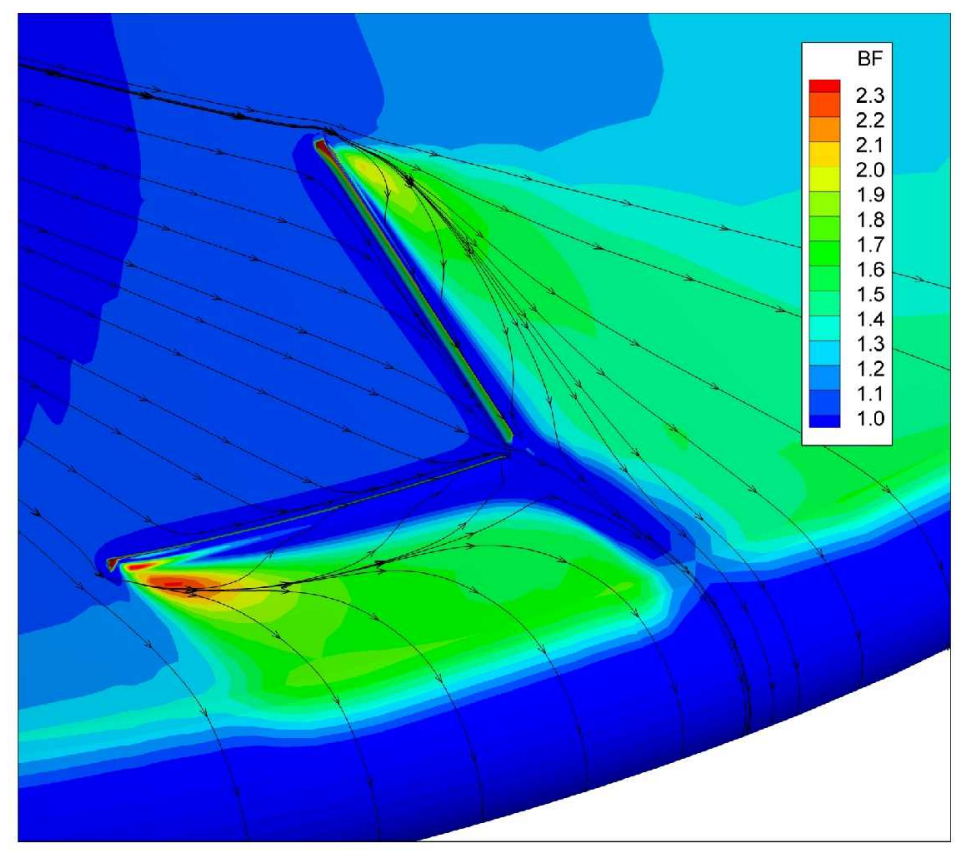

Figure 13. Turbulent heating "bump factor" for a 0.4" V-shaped gap filler (Ref. 140).

A detailed analysis of transient heating effects due to RCS thruster impingement has not been performed for any Mars mission prior to MSL, in large part because most previous missions have been spin-stabilized ballistic entries. In fact, the first Mars-related flight RCS calculations were recently performed by Dyakonov et al. ${ }^{139}$ in order to quantify potential aerodynamic-RCS interaction effects for Mars Phoenix at supersonic speeds. However, heating due to RCS thruster impingement is an important issue for MSL because the vehicle is hypersonically guided, and thus the thrusters will be firing throughout the hypersonic portion of the entry. The plumes from these thrusters will interfere with the baseline flowfield, and the resulting shock and vortex structure could impinge on the backshell, causing localized augmented heating. The location and magnitude of augmented heating are a function of the oncoming flow field and are sensitive to the computational grid density. Steady-state CFD of an earlier design ${ }^{77}$ indicated that the presence of an RCS plume could cause transient localized heating about 3-5 times larger than the 
baseline levels as shown in Fig. 14. These elevated heat fluxes would have exceeded the heat flux limits for the Mars heritage spray-on SLA-561S backshell TPS material. ${ }^{77}$ Unfortunately, no experimental data currently exist to enable a validation of the methods employed, and therefore large uncertainty factors must be placed on both the magnitude and location of the predicted augmented heating. As a result, the MSL program decided to replace the SLA-561S material on the backshell with the SLA $561 \mathrm{~V}$, used as a forebody material in previous missions. SLA$561 \mathrm{~V}$ can withstand heat fluxes in excess of $100 \mathrm{~W} / \mathrm{cm}^{2}$, and thus will be sufficient to handle the augmented backshell heating, but with a significant mass and cost penalty over the baseline design. Interestingly, the program subsequently altered the design of the RCS system to a thruster pattern that is predicted to produce much milder interference heating, ${ }^{133}$ but this change occurred too late to further impact backshell TPS selection. Additional work, particularly high-fidelity transient flow analysis and validation data (ground and flight), is needed to better assess the ability of modern computational tools to predict such flow events.

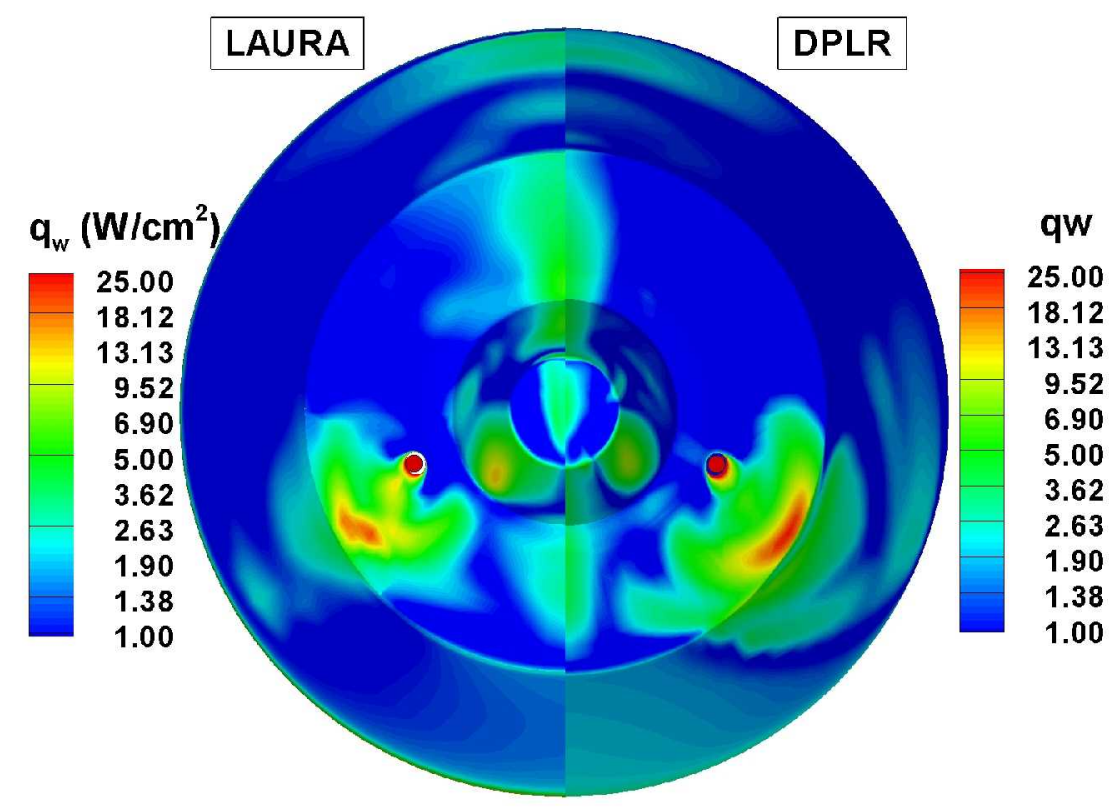

Figure 14. Predicted zero-margin afterbody heat flux on MSL during an RCS thruster firing (Ref. 77).

\section{UNCERTAINTY ANALYSIS}

Recent advances in computational performance have enabled much more rigorous analysis of the uncertainties associated with computational aeroheating predictions. For example, Bose et al. ${ }^{107}$ introduced a technique in which parametric modeling uncertainties are determined for a given reentry problem by directly coupling a non-equilibrium CFD solver to a Monte-Carlo based statistical analysis package. The underlying methodology and application to reentry aerothermodynamics and TPS design was detailed by Wright et al. ${ }^{134}$ An analysis of Mars Pathfinder convective heating was performed by Bose et $\mathrm{al}^{80}$ at several trajectory points. In order to investigate the impact of catalysis on the overall heating uncertainty, the parametric model discussed in Section 4 was incorporated into the analysis. In this manner a structural uncertainty was parametrically bounded so that it could be explored with a standard Monte-Carlo technique. Since the actual catalytic properties of the surface are unknown, three analyses were performed, for a highly, moderately, and weakly catalytic wall. In addition, a fourth analysis was performed assuming a supercatalytic wall. Each of these regions is indicated on Fig. 2.

In addition to the two catalytic modeling parameters $\left(\gamma_{c a t}\right.$ and $\left.p_{2}\right), 128$ other independent input parameters were varied, including chemical reaction rates, vibration-dissociation coupling parameters, vibrational relaxation times, and the binary collision integrals that make up mixture transport properties. The key results of this study are summarized in Table 2 . The nominal heating rate varied from $121 \mathrm{~W} / \mathrm{cm}^{2}$ for a supercatalytic wall to about 47 $\mathrm{W} / \mathrm{cm}^{2}$ for a weakly catalytic surface, a factor of 2.5 in the predicted heat flux. More importantly, uncertainty estimates of the heat flux were determined in each catalytic regime. It can be seen that the supercatalytic and weakly catalytic cases have roughly symmetric uncertainty distributions of approximately $\pm 10 \%$ on predicted heating. On the other hand, the highly and moderately catalytic walls exhibit asymmetric uncertainty distributions. The largest uncertainties by far are for the moderately catalytic surface. 
Table 2. Pathfinder stagnation point heating

\begin{tabular}{lccc}
\hline $\begin{array}{c}\text { Level of } \\
\text { Catalycity }\end{array}$ & $\boldsymbol{q}_{w}$ & $\begin{array}{c}\text { 95\% confidence } \\
\text { limits } \\
(\%)\end{array}$ \\
\hline Supercatalytic & 120.6 & +10.3 & -9.9 \\
Highly catalytic & 106.7 & +12.0 & -17.2 \\
Moder. catalytic & 74.0 & +41.0 & -33.6 \\
Weakly catalytic & 47.2 & +11.7 & -10.6 \\
\hline \hline
\end{tabular}

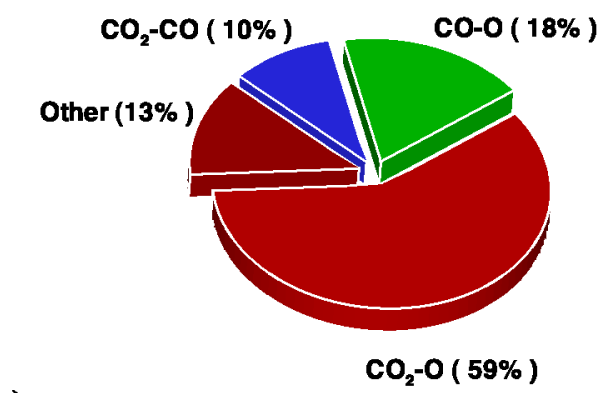

a)

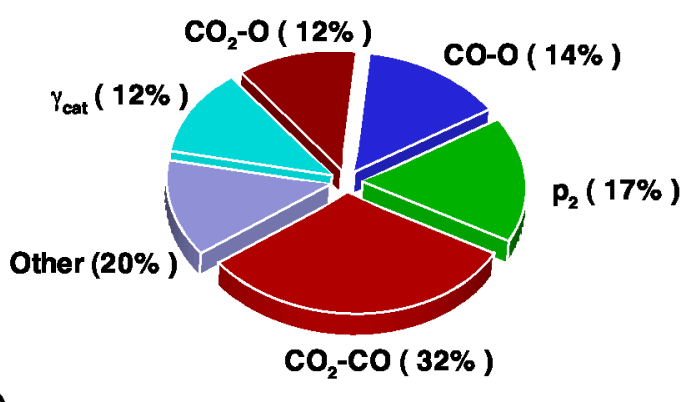

b)

Figure 15. Principal contributors to Pathfinder heat flux uncertainty for a) supercatalytic, and b) highly catalytic wall assumption (Ref. 80).

Figure 15 shows the key input contributors to the total uncertainty of a supercatalytic and highly catalytic surface as determined via linear regression analysis. It is apparent that only a few of the 130 parameters are significant contributors to the uncertainty in heat flux, and that the relative importance of the key parameters varies considerably for the different catalysis assumptions. For the limiting case of a supercatalytic wall, nearly all of the parametric uncertainty comes from collision integrals that govern the diffusion rate of reactants to the surface. The highly catalytic wall is in the diffusion limited regime, and thus the majority of the uncertainty again comes from collision integrals, although the preference factor $p_{2}$ is also important. Similar results were obtained for the moderately and weakly catalytic wall assumptions. ${ }^{80}$

From a design standpoint, an improved understanding of catalysis would have a significant impact on TPS selection and design for future Mars entry missions; clearly a peak heating rate of $47 \mathrm{~W} / \mathrm{cm}^{2}$ would result in lower TPS mass than $121 \mathrm{~W} / \mathrm{cm}^{2}$. One of the strengths of this technique is that it can help to determine how much improvement is required for a given mission or material selection. For example, $\gamma_{\text {cat }}$ contributes $94 \%$ of the total uncertainty for the moderately catalytic wall, but only $12 \%$ for the highly catalytic and weakly catalytic surfaces. ${ }^{80}$ Therefore, if testing determined that a given material performed either as a highly or weakly catalytic surface, the presented analysis indicates that further refinement in our knowledge of $\gamma_{c a t}$ may not be necessary, and additional research monies could be targeted to other risk drivers. However, if the material were determined to be moderately catalytic the resulting heating uncertainties could be greatly reduced if the uncertainty of $\gamma_{\text {cat }}$ were further refined.

It is important to note that the analysis presented here is only as good as the underlying physical models employed. Uncertainty analysis alone cannot characterize or bound structural uncertainties in the models; these must be exposed via ground or flight testing. This fact was made evident in the aerothermal design of MSL, ${ }^{133}$ where it was clearly shown that the parametric uncertainties that can be quantified via Monte-Carlo analysis were a small portion of the overall aeroheating uncertainty budget, which was driven by structural uncertainties in the roughness induced heating and turbulence models.

\section{Ground Test Aeroheating Data}

Ground test aeroheating data fall into two broad categories: perfect gas (typically either air or $\mathrm{N}_{2}$ ) data obtained in conventional blowdown hypersonic wind tunnels, or high-enthalpy, chemically-reacting flow data obtained in short-duration impulse (shock, reflected-shock or shock-expansion tube) facilities. Both classes of facilities have advantages and disadvantages. Conventional wind tunnels provide high-productivity, clearly defined operating conditions, and low measurements uncertainties, but operate at low enthalpies that cannot reproduce the chemical kinetics of hypervelocity atmospheric entry. These tunnels are best suited for configuration and parametric 
trade studies, investigation of transition phenomena, and acquisition of baseline (without chemistry) data for code validation. Impulse facilities provide high-enthalpy test environments in which the effects of chemical kinetics appropriate to re-entry conditions can be investigated in the desired test gas (e.g. $\mathrm{CO}_{2}$ for Mars), however test uncertainties are generally higher than in conventional facilities due to lack of repeatability/ability to specify test conditions, flow establishment concerns within the limited test time (micro- to millisecond), and noise produced by the dynamic operating environment. The current section is not intended to present a complete review of all Mars relevant ground testing, but rather to highlight the application of key aeroheating facilities to better understand and quantify key uncertainties in the aeroheating environment for Mars entry.

\section{A. Ground Test Results}

Hollis and Perkins performed a series of experiments in the Hypulse expansion tube facility on a Mars entry configuration very similar to Pathfinder. ${ }^{108}$ Tests were conducted in both air and $\mathrm{CO}_{2}$ using a $5.08 \mathrm{~cm}$ diameter Macor model instrumented with thin film gages on both the forebody and sting. The $\mathrm{CO}_{2}$ tests were all run at the nominal condition $V=4.8 \mathrm{~km} / \mathrm{s}$ and $\rho=5.8 \times 10^{-3} \mathrm{~kg} / \mathrm{m}^{3}$, a condition relevant to typical Mars entries. Computational simulations of these tests generally showed good agreement with the forebody heating data when a non-catalytic wall boundary condition (chosen because the Macor ceramic surface was assumed to be non-catalytic) was employed. ${ }^{109}$ Figure 16 shows a sample computation and comparison to experimental data for two $\mathrm{CO}_{2}$ shots. Afterbody heating data were slightly underpredicted using this methodology. These tests marked some of the first high-enthalpy Mars atmosphere aerothermal validation data obtained in support of NASA missions.

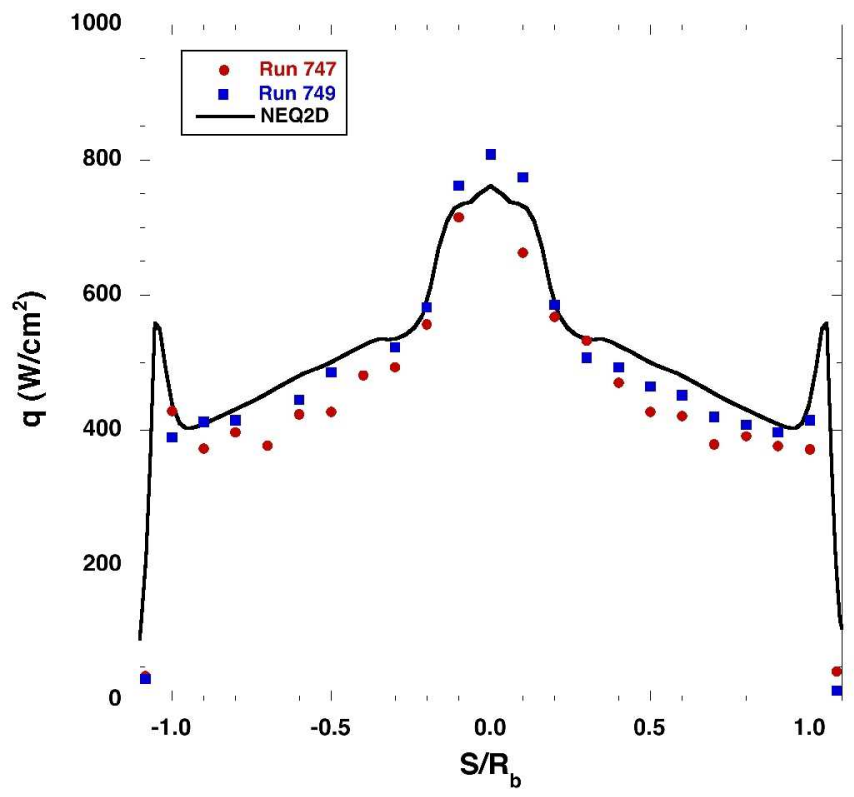

Figure 16. Comparison of CFD prediction (using NEQ2D code) and experimental data from two shots on $7^{\circ}$ sphere-cone model in HYPULSE facility. Adapted from Ref. 109.

Ground based aeroheating testing was not an important component of the design of the MER, MPL, and Phoenix missions, primarily because the expected heating environment was benign compared to Pathfinder (see Table 1). However, the MSL mission presents a new challenge due to the high likelihood of turbulent transition and the predicted high heating and shear stress on the leeside of the aeroshell, as discussed in Section 5. As a consequence, an extensive test series was planned in support of MSL TPS design.

Several tests have been conducted recently in perfect-gas facilities to support the MSL mission. During the mission concept-development phase, the entry vehicle was to be bolted to the cruise stage through the forebody heat shield. Testing of various cavity diameters and locations in the NASA Langley 20-inch Mach 6 Air Tunnel ${ }^{110-111}$ showed that these penetrations would produce turbulent wedges on the forebody at Reynolds numbers well below those of natural smooth-body transition. Figure 17 is a sample thermal phosphor image from this test series. Warmer colors (oranges and reds) in Fig. 17 indicate higher temperature (and therefore heat flux). Wedges of elevated heating can clearly be seen downstream of the simulated penetrations. The resultant transitional/turbulent heating was found to be greater than predicted for fully turbulent flow. Concurrent testing was performed to examine the 
aeroheating on possible trim tabs or other control surfaces, intended to increase lift and enable more precise control of the landing error ellipse. ${ }^{88}$ Later designs of the MSL mission eliminated both forebody penetrations and fixed trim surfaces, and thus experimental work in this area was stopped. More recently a new test series ${ }^{112}$ using larger models in the same facility was performed to obtain natural transition to turbulence. A complimentary test series was also conducted in the Arnold Engineering Development Center (AEDC) Tunnel 9 in $\mathrm{N}_{2}$ at Reynolds numbers up to 49 million per foot in order to obtain a fully turbulent flowfield on the MSL aeroshell. ${ }^{113}$ The naturally transitioned heating levels from the Mach 6 test was about 15\% higher than predictions using the Baldwin-Lomax turbulence model (Figure 18), while the experimental data from AEDC was in excellent agreement with predictions, even on the windside shoulder region. Note that the model cone angle in Fig. 18 was $60^{\circ}$, chosen to facilitate natural transition in the Langley Mach 6 tunnel.

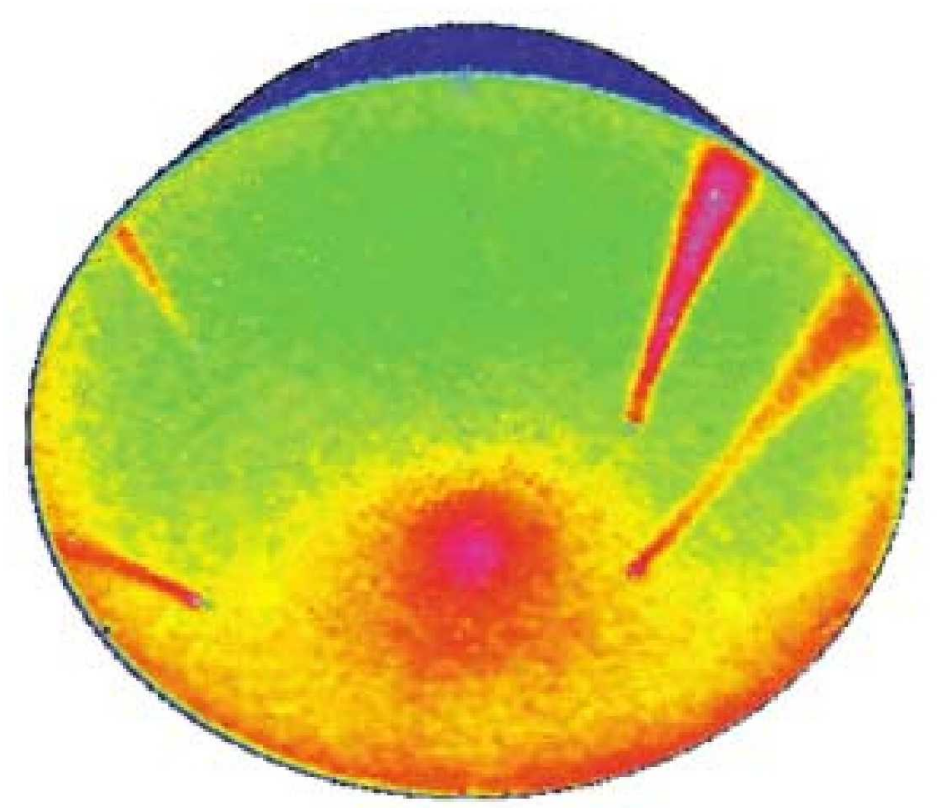

Figure 17. Turbulent wedges formed behind forebody penetrations in LaRC Mach 6 tunnel (Ref. 110).

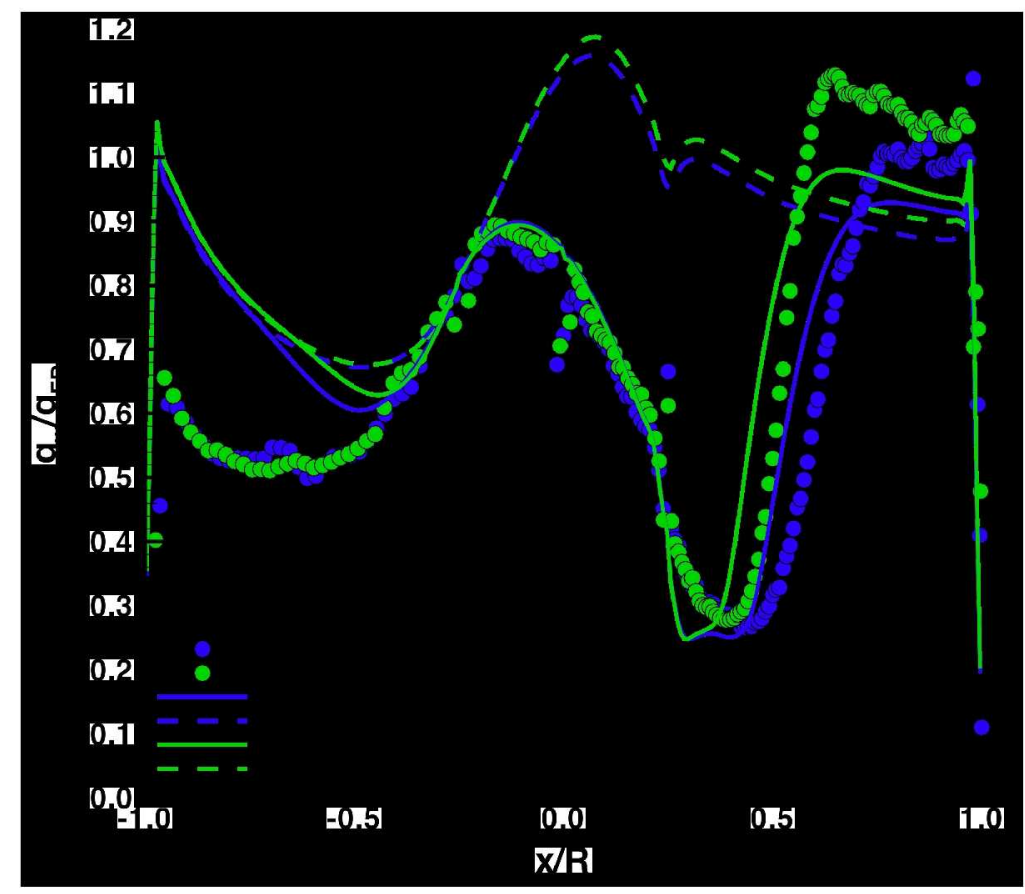

Figure 18. Turbulent heating predictions and data from the LaRC Mach 6 tunnel. 
a)
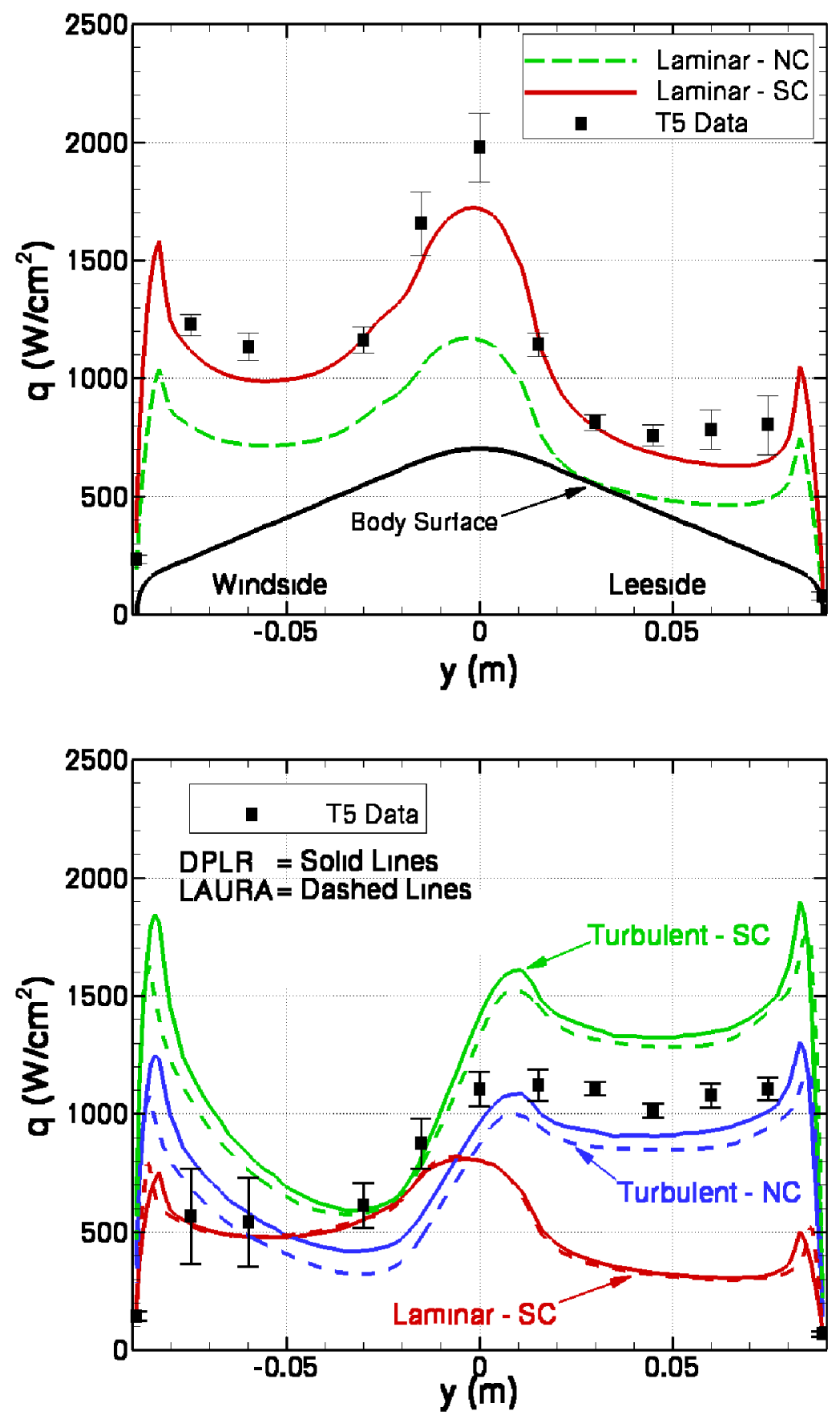

b)

Figure 19. Comparison of simulation to T5 data for a) Shot 2257, and b) Shot 2258. (Ref. 114).

High-enthalpy, impulse facility tests have also been conducted in the T5 shock tunnel at the California Institute of Technology ${ }^{114}$ and the LENS shock tunnel at the CalSpan University of Buffalo Research Center (CUBRC) ${ }^{115-116}$ in support of MSL. These tests were conducted in $\mathrm{CO}_{2}$ at enthalpies and Reynolds numbers representative of the flight environment, although the Mach number was much smaller, since much of the freestream enthalpy in shock tunnel facilities is contained in the thermal and chemical modes of the gas, rather than the kinetic mode. Heat transfer data were obtained for laminar, transitional, and fully turbulent flows. The data from both facilities clearly indicate that the leeside turbulent heating augmentation predicted by flight CFD calculations is 
qualitatively valid and must be accounted for during the design of the TPS. Figure 19a shows a comparison of noncatalytic (NC) and supercatalytic (SC) CFD simulations with T5 data for a laminar case (Shot 2257: $h_{0}=11.7$ $\mathrm{MJ} / \mathrm{kg}, p_{0}=19.4 \mathrm{MPa}, \alpha=11^{\circ}$ ). The supercatalytic simulation is in generally good agreement with the data, while the non-catalytic case significantly under-predicts the measured heating rates. Figure $19 \mathrm{~b}$ shows a similar comparison for a case with turbulent leeside heating (Shot 2258: $h_{0}=4.9 \mathrm{MJ} / \mathrm{kg}, p_{0}=63.9 \mathrm{MPa}, \alpha=11^{\circ}$ ). Computed results are shown for two commonly used NASA-developed aeroheating CFD codes (DPLR ${ }^{136}$ and LAURA $^{135}$ ). For this case, we see that the best agreement is achieved on the turbulent leeside $(y>0)$ when a noncatalytic wall assumption is employed, while the windside appears to remain laminar. By examination of all shots in the series, the leeside heating augmentation due to turbulence was shown to be inversely related to the freestream enthalpy ${ }^{114}$ Changes in angle of attack between $11^{\circ}$ and $16^{\circ}$ were shown to have minimal impact on both measured and computed heat transfer for both laminar and turbulent flows. ${ }^{114}$ The dominant leeside transition mode was shown to be axial, rather than crossflow induced, at angles of attack up to $16^{\circ}$.

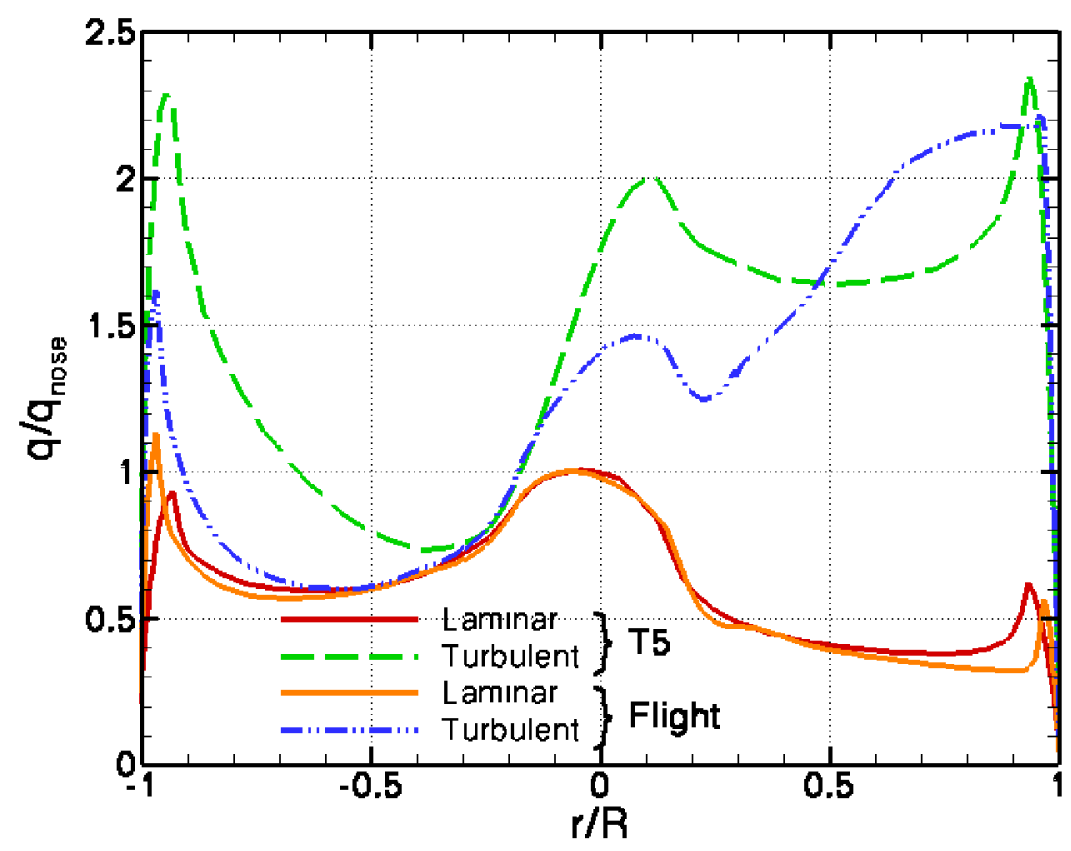

Figure 20. Normalized comparison of MSL T5 and flight simulations.

Figure 20 shows computed heating from Shot 2258 from the T5 experimental series as well as the flight peak heating point shown in Fig. 4. In each case the turbulent solution was generated with the Baldwin-Lomax turbulence model, and all solutions were run assuming a supercatalytic wall. Each case has been normalized by the body diameter and the computed laminar heating at the geometric apex of the sphere-cone. From Fig. 20, we see that the two laminar solutions are very similar (slight differences at the shoulder are due to the fact that the T5 model had a larger shoulder radius than the current flight design). On the other hand, the turbulent solutions show significant differences. In particular, in the experiment the apex region is predicted to have higher turbulent heating than the leeside of the cone. This same trend is observed in ground test data from LENS, LaRC Mach 6, and T9 on this aeroshell shape as well. In contrast, at flight conditions the heating increases rapidly down the length of the cone, reaching a level much higher than the apex. The windside shoulder is also predicted to be much hotter in the tunnel than in flight. While both cases exhibit a similar peak turbulent heating augmentation factor (approximately $2.25 \times$ the laminar heating at the geometric apex), the differences in the heating profiles imply significant differences between the facility and flight environments. While the CFD results agree reasonably well with the T5 data, it is unknown at this time how well the CFD will predict the flight environment. This question of ground to flight traceability means that flight heating uncertainties will remain high until the codes have been properly validated with flight data.

Finally, the data from T5, LENS, and the Langley Mach 6 air tunnel were examined by Hollis et al. ${ }^{112}$ in an attempt to deduce a "universal" transition correlation for transition onset on the leeside of blunt sphere-cone configurations. In general, the transition data from each facility, plotted in terms of $\operatorname{Re}_{\theta} / \mathrm{M}_{e}$, correlated well across its 
range of operating conditions. However, no definitive correlation was found that could be applied across all facilities. The later determination that shock standoff distances were grossly mispredicted by CFD in the LENS tests (see the following section), makes any transition analysis from that facility suspect. Clearly, a much greater range of data will be required in order to resolve the effects of gas composition, enthalpy, chemical kinetics, facility noise, Mach and Reynolds numbers, etc. on sphere-cone transition.

\section{B. Testing Anomalies}

The MSL test program in T5 and LENS was deemed important to the mission, because those facilities permit testing of natural turbulence in the correct gas at flight-like enthalpies. However, the results raised almost as many new questions as they answered. For example, the models in both facilities were constructed of stainless steel, but the LENS model was initially coated with $\mathrm{SiO}_{2}$ in an attempt to produce a non-catalytic response, while the T5 model was uncoated. Despite this, the trends in laminar and leeside turbulent heating shown in Fig. 18 were common across all shots in both facilities; CFD simulations were generally in good agreement with the laminar data as long as a supercatalytic wall model was employed, while turbulent simulations were in reasonable agreement when a non-catalytic wall model was used. This conclusion is quite different from that of Hollis and Perkins, ${ }^{109}$ who demonstrated that a non-catalytic wall boundary condition gave the best agreement to laminar heat transfer data from Hypulse, as well as Kolesnikov and Marraffa, ${ }^{71}$ who clearly demonstrated that borosilicate coated tiles and glass-silicide coated carbon-carbon showed weakly catalytic response in a strongly dissociated subsonic plasmatron $\mathrm{CO}_{2}$ flow. In an attempt to better understand the effects of surface catalysis on model heating, a second LENS experimental model was constructed with coaxial gages, silver calorimeters, and thin film gages on the same model. ${ }^{116}$ All instrumentation types produced heating data that were consistent with each other as well as previous data from LENS and T5. These results are even more confusing when attempts to measure surface catalysis of metals in dissociated $\mathrm{CO}_{2}$ are accounted for as discussed in Section 3 . These tests ${ }^{76}$ all indicate that the surface of the model should be weakly catalytic to $\mathrm{O}_{2}$ recombination, and nearly non-catalytic to $\mathrm{CO}_{2}$ recombination, a conclusion that is clearly at odds with the observed heat transfer data. The reasons for this discrepancy are not known at this time, but obviously point to a deficiency in current models for gas-phase $\mathrm{CO}_{2}$ chemistry, surface kinetics, turbulence modeling, or some combination of the three.

A second anomaly was discovered when the Schlieren images from the LENS shots were examined. These images revealed that the shock standoff distance was about twice what was predicted by CFD. ${ }^{117}$ In contrast, the agreement between the experiment and computation was excellent in T5 shots. MacLean and Holden ${ }^{117}$ proposed that the disparity was produced by a mis-prediction of the amount of freestream energy contained in either the vibrational or chemical mode of the gas, and demonstrated parametrically that this effect could result in shock standoff distances comparable to those observed. Although the authors provided no direct evidence of this phenomenon, it appears reasonable when previous studies of the freestream energy content of (presumably much simpler) pure $\mathrm{N}_{2}$ flows in LENS are considered. ${ }^{118}$ If freestream nonequilibrium effects are the root cause of the shock standoff discrepancies observed in LENS, this could also explain why the T5 data were free of this effect; the freestream densities in the T5 shots were 2-3 orders of magnitude higher than those in LENS, leading to a much more equilibrium test condition. The anomalously large shock standoff distance observed in the LENS facility has called in to question the validity of using shock tunnels for evaluating nonequilibrium phenomena in $\mathrm{CO}_{2}$. Fortunately, CUBRC has nearly completed construction and testing of a new expansion tunnel facility on the site, labeled LENS-XX, ${ }^{147}$ that promises the possibility of a high enthalpy freestream in which nearly all of the energy is in the kinetic (rather than internal) modes of the gas. Such a facility would provide a much more flight-like environment. Initial runs in this facility have shown that the measured and predicted shock standoff distance for high enthalpy $\mathrm{CO}_{2}$ shots are in excellent agreement. However, more extensive validation is required.

A third question was raised because, in addition to the leeside transition observed in all of the tests discussed, heating augmentation in the windside stagnation-region was also observed in most of the high Reynolds number LENS test data. ${ }^{112}$ This effect was also evident in an incipient (weaker) form of this phenomenon observed in the perfect-gas Mach 6 Air data, ${ }^{12}$ the perfect-gas $\mathrm{N}_{2}$ data from AEDC Tunnel $9^{113}$ (Figure 21) and the T5 $\mathrm{CO}_{2}$ tests. ${ }^{114}$ Interestingly, the effect was much weaker in T5 than LENS, although the test conditions were roughly equivalent in terms of enthalpy and momentum thickness Reynolds number. A review of Viking era aeroheating testing in the NASA Langley Mach 8 Variable Density Hypersonic Tunnel indicates several high Reynolds number tests where a similar incipient stagnation point heating augmentation was observed. ${ }^{119}$ Finally, recent testing of the CEV capsule has shown similar stagnation anomalies on a spherical-segment heatshield in air. ${ }^{148}$ The reasons for this phenomenon are also not known at this time, but its occurrence over such a wide range of facilities indicates that it is likely a real effect rather than a facility problem. 


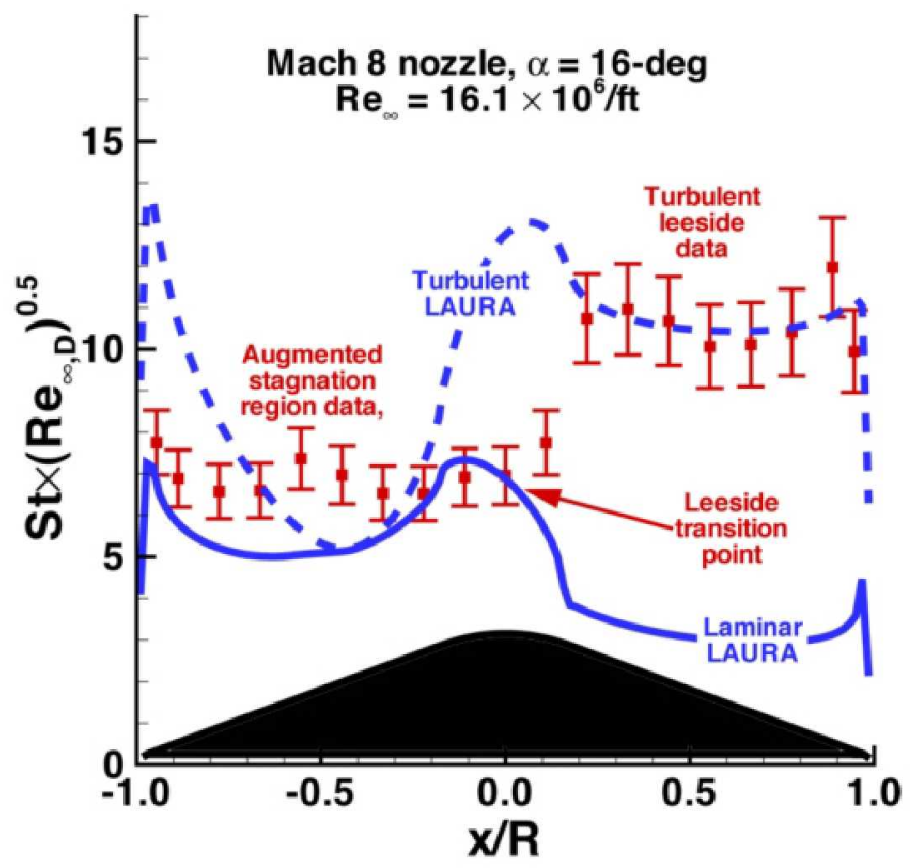

Figure 21. Augmented stagnation region heating in AEDC Tunnel 9 testing.

\section{Flight Data}

The "gold standard" for validating entry aeroheating and TPS material response models is with flight data. Unfortunately such data are scarce for non-Earth entries, and the recent trend has been to eliminate engineering instrumentation from planetary entry missions as a cost saving measure. For example, the MER landers included no instrumentation, and none is planned for Phoenix in 2007. The next opportunity to obtain flight aeroheating data is the MSL mission. A basic set of relatively mature low risk engineering instruments in the heatshield and backshell (including thermocouples, recession sensors, and pressure taps) could go a long way toward answering some of the key questions discussed in previous sections of this review.

A small amount of engineering flight data is available from two previous Mars missions: Viking and Pathfinder. In addition, the MER Opportunity rover conducted a visual observation campaign of its aeroshell in early 2005 as part of its extended mission. These data sources are briefly discussed below.

\section{A. Mars Viking I \& II}

The Viking program included two landers that entered the Martian atmosphere in July and September of 1976. Both probes were $70^{\circ}$ sphere-cones with an ablative forebody heatshield made of SLA-561V, which was injected into a phenolic fiberglass honeycomb structure. The Viking probes flew a lifting entry at a nominal angle of attack of $11^{\circ}$, and entered at a relative velocity of about $4.5 \mathrm{~km} / \mathrm{s} .{ }^{120}$ The heatshield of each entry vehicle was instrumented with a mass spectrometer, five pressure transducers and a stagnation temperature sensor, which was deployed through the heatshield at a detected velocity of $1.1 \mathrm{~km} / \mathrm{s}$. All heatshield instrumentation function nominally for both Viking entries. On the backshell, each entry vehicle included a single base pressure transducer and two surface-mounted aftbody temperature sensors - one on the fiberglass inner cone and one on the aluminum skin of the outer cone. ${ }^{91}$ Three of the four backshell temperature sensors worked correctly, but the sensor on the aluminum outer cone of the Viking I entry vehicle failed near the peak heating point. ${ }^{91}$ Pre-flight analysis predicted afterbody heating to be $3 \%$ of the forebody stagnation point heating rate, ${ }^{91}$ but flight data indicated that the peak heating was actually more than $5 \%$ of the stagnation value. The high heating levels, as well as the slope change observed in heating rate vs. Reynolds number at $\operatorname{Re}_{D} \sim 5 \times 10^{5}$, were believed to be evidence of turbulent transition on the base. ${ }^{121}$

Edquist et al ${ }^{94}$ recently reanalyzed the thermocouple data and explored the impact of material response and entry trajectory uncertainties on the resulting measured heating rates. In addition, detailed CFD simulations were performed with two different codes at eleven points along the entry trajectory for Viking I. The results of this analysis indicated that the wake flowfield was predicted to be unsteady even at low Reynolds number. ${ }^{94}$ As shown in Fig. 22, the temporally averaged computational results generally underpredict the measured heating rates (by as 
much as a factor of three), particularly on the aluminum base cover near the peak heating point. This level of agreement is much worse than was obtained for similar Earth entry data. ${ }^{86}$ While some of the disagreement may be due to ambiguities in the flight dataset, additional flight data in a Mars entry environment are clearly required to reduce uncertainty levels for Mars entry afterbody heating.

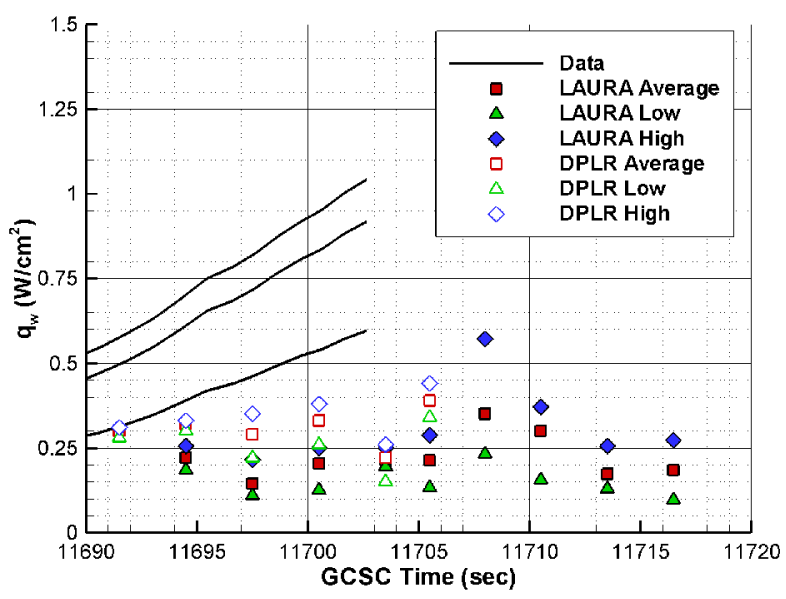

a)

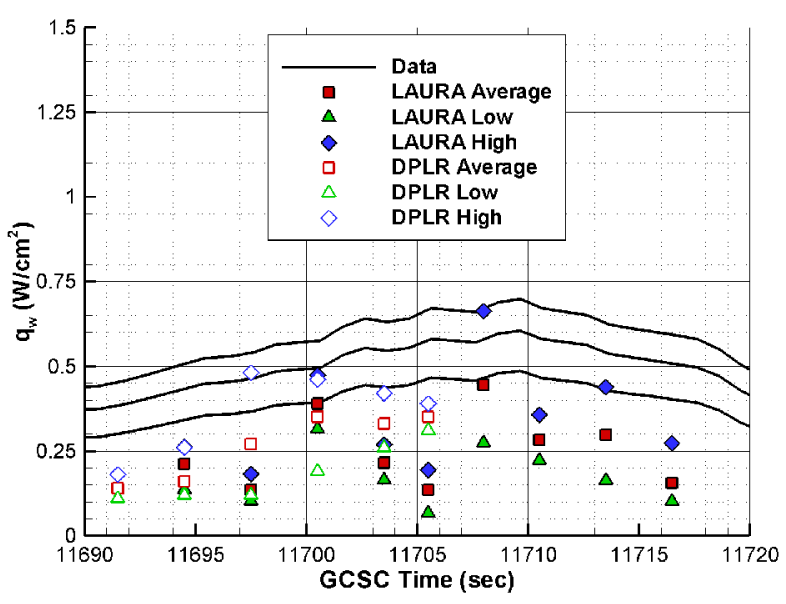

b)

Figure 22. Comparison of Viking afterbody flight data and computed heat transfer; a) aluminum cone, and b) fiberglass cone (Ref. 94).

\section{B. Mars Pathfinder}

Mars Pathfinder successfully entered the Martian atmosphere on July 4, 1997. ${ }^{9}$ The forebody TPS for this mission was SLA-561V, nearly identical to that employed on Viking. ${ }^{122}$ The majority of the afterbody was protected by SLA-561S, a spray-on version of the forebody material. The backshell interface plate (BIP) and a section near the rear corner were covered with silicone impregnated reusable ceramic ablator (SIRCA) tiles. The aeroshell was instrumented with nine thermocouples at various depths in the TPS material and three platinum resistance thermometers (PRT). ${ }^{122}$ Six of the nine thermocouples returned usable data, although the results from the forebody thermocouples are somewhat ambiguous due to anomalous behavior of the PRT's used to calibrate the raw data. ${ }^{105}$ The only post-flight analysis of these data to date was performed by Milos et al. ${ }^{105}$ Forebody results showed that the measured temperatures were consistent with a total incident aeroheating about $85 \%$ of the fully catalytic value at the stagnation point and shoulder. Detailed calculations were not performed on the afterbody; however Milos et al. ${ }^{105}$ showed that measured in-depth temperatures implied incident heating rates that were significantly lower than preflight predictions. ${ }^{24}$

\section{Mars Exploration Rovers - Opportunity}

The twin MER spacecraft entered the Martian atmosphere in January 2004. Once again, the forebody TPS was SLA-561V, and the afterbody was protected with SLA-561S. Although neither aeroshell included any flight instrumentation, a unique opportunity afforded itself after both rovers lasted well beyond their planned lifetimes. During their extended missions, it was proposed that the Opportunity rover drive to a location near the discarded forebody heatshield and conduct visual observations with the cameras and micro-imager in an attempt to deduce its performance during the entry. ${ }^{123}$ A complimentary proposal to employ the Rock Abrasion Tool (RAT) to scrape away the surface of the TPS and directly examine the underlying char was not pursued when testing at the Jet Propulsion Laboratory (JPL) indicated that the RAT could become clogged with the charred TPS material. The MER heatshield observation campaign included imagery of the TPS char layer, main seal, substructure, and thermal blankets. Although detailed imagery was difficult due to the fact that the aeroshell inverted and broke into multiple pieces on impact with the Martian surface, good data were obtained at several locations. Figure 23 shows a sample of the type of image obtained. This image depicts a section of the heatshield that was originally near the shoulder of the spacecraft. This section of the heatshield was broken upon impact, allowing the camera to take a cross sectional view if the carbon polyimide face sheets, aluminum honeycomb substructure, and TPS material. A detailed analysis of the data has not been performed to date, but with the release of the best estimated reconstructed entry trajectory ${ }^{124}$ such an analysis should be relatively straightforward. 


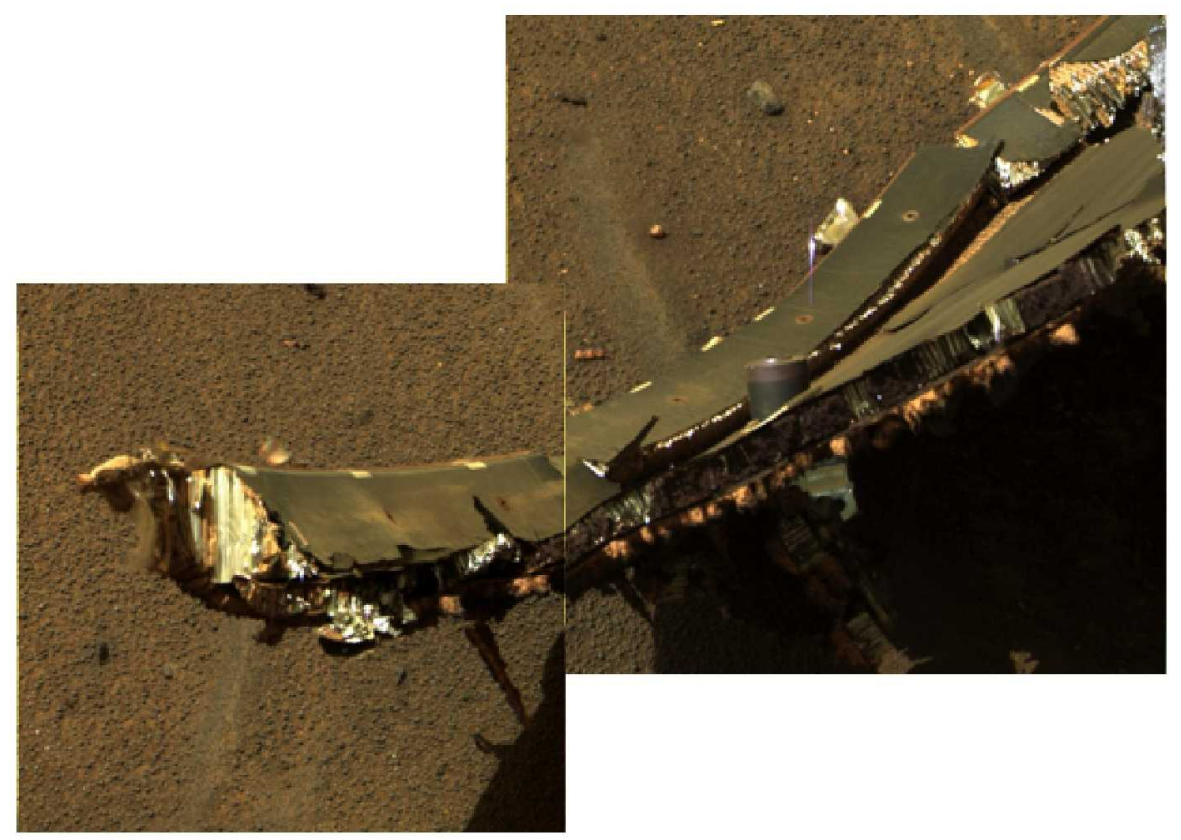

Figure 23. MER-B heatshield on the surface of Mars as imaged by the Opportunity rover (Ref. 123).

\section{Mars Science Laboratory}

MSL is scheduled for launch in late 2011 and Mars arrival in 2012. Fortunately, NASA has authorized a program called MEDLI (MSL Entry, Descent and Landing Instrumentation) to instrument the MSL forebody heatshield with seven TPS plugs, each containing four type-K thermocouples and an advanced recession sensor, ${ }^{125}$ as well as seven pressure ports configured as a flush air data system (FADS). ${ }^{126}$ One thermocouple in each plug is located near to the surface to permit a reconstruction of the aeroheating environment. Figure 24 shows the location of all heatshield instrumentation. In Fig. 24, the white symbols labeled with a "T" are the thermocouple plug locations, while the black symbols labeled with a "P" are the pressure ports. The symbols are not to scale. No instrumentation is included on the backshell due to MSL schedule constraints. This dataset will provide the first new Mars entry aeroheating data since Pathfinder, and will hopefully help to answer some of the fundamental questions discussed in this review relating to leeside turbulent heating levels, forebody transition, windside heating augmentation, catalytic heating levels, and the recession rate of PICA in a high heating environment.

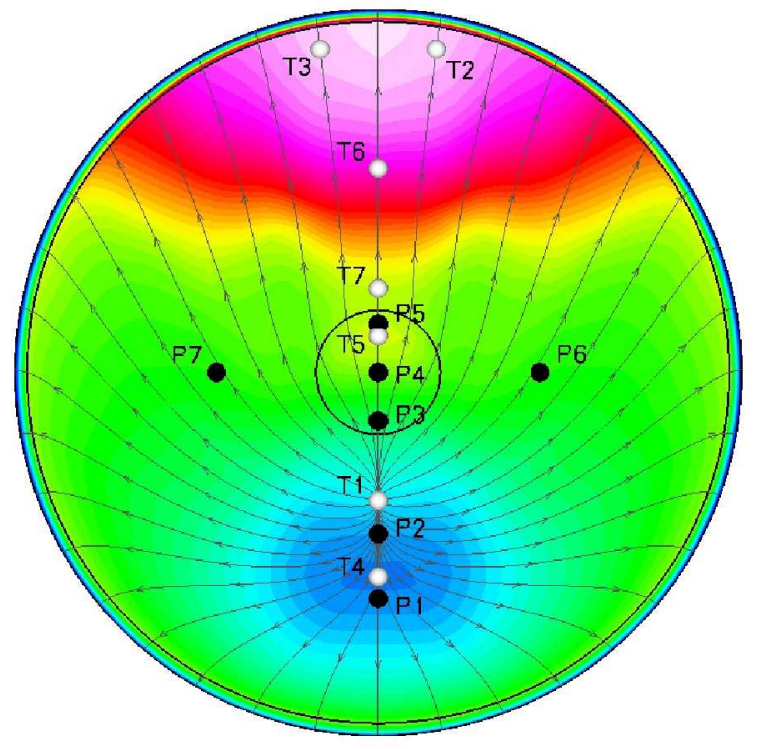

Figure 24. MEDLI instrumentation locations on the MSL heatshield. 


\section{Summary ANd ConClusions}

The current state of the art for computational and experimental aerothermal analysis for Mars entry missions is reviewed. The aeroheating environment of all Mars missions to date has been dominated by laminar convective heating. The primary uncertainty in our ability to predict forebody laminar convective heating is surface catalysis in a $\mathrm{CO}_{2}$ environment. The status of model development and ground-based testing in this area is briefly reviewed. Current design models assume a conservative upper limit for catalytic heat transfer, which implies that significant performance gains may be possible if this effect were better characterized. Upcoming missions, including the Mars Science Laboratory in 2011, will experience early transition to turbulence due to a combination of large size and high ballistic coefficient. Transition location and the resulting turbulent heating levels on the blunt, lifting cones employed for entry are another large source of uncertainty. Future missions, particularly crewed vehicles, will encounter additional heating from shock-layer radiation due to a combination of larger size and faster entry velocity. Unlike the case for Earth entries, no validated model for shock layer radiation in a $\mathrm{CO}_{2}$ environment currently exists, although some recent developments in the literature are discussed. The applicability of a rigorous Monte-Carlo methodology for identifying and quantifying the sensitivities and uncertainties inherent in the physical models employed to predict these phenomena is introduced. Results for Mars Pathfinder indicate that the majority of the prediction uncertainty in laminar convective aeroheating is due to poor knowledge of the catalytic mechanism, as well as uncertainties in several key collision integrals that are used to determine transport properties. The need for fully coupled analysis that combines TPS material response and aerothermal prediction uncertainties is identified. Capabilities of ground test facilities to support aeroheating validation are also summarized. In particular, shock and expansion tunnels, which can produce flight-like enthalpy and Reynolds numbers, are shown to have value for code validation purposes, although transition data from such facilities are difficult to characterize due to tunnel noise effects. Finally, engineering flight data from the Viking and Pathfinder missions, as well as imagery from the MERB heatshield observation campaign, are discussed. These data clearly have utility for code validation studies, although minimal effort has been expended to date on this activity. The upcoming MSL mission will return pressure, temperature, and TPS recession data that will be used to better understand how pre-flight heatshield design environments compare to those actually encountered.

\section{ACKNOWLEDGEMENTS}

The authors thank Christine Szalai (Jet Propulsion Laboratory) for information about and images from the MER-B heatshield observation campaign, Bill Willcockson (Lockheed Martin Space Systems) for discussions on Pathfinder, MER, and Phoenix mission design, Artem Dyakonov (NASA Langley Research Center) for discussions and figures regarding RCS impingement heating augmentation on MSL, Ryan McDaniel (NASA Ames Research Center) for information on Mars Phoenix, Jim Brown (NASA Ames) for discussions on distributed roughness effects on heating, and Michael Barnhardt (Eloret Corporation) for discussions on the applicability of DES methods for hypersonic base flow simulations. Mark Loomis (NASA Ames) performed the MER computations shown in Figure 7. Special thanks are due to Rob Manning (Jet Propulsion Laboratory), Adam Steltzner (Jet Propulsion Laboratory), Eric Slimko (Jet Propulsion Laboratory), Michelle Munk (NASA Langley), Bonnie James (NASA Marshall Spaceflight Center), and Ethiraj Venkatapathy (NASA Ames), for supporting this work and offering countless helpful suggestions. A portion of the funding for this work was provided by the In-Space Propulsion program under task agreement M-ISP-03-18 to NASA Ames, as well as the Mars Science Laboratory and Exploration Technology Development Programs.

\section{REFERENCES}

[1] Messina, P., Vennemann, D., and Gardini, B., "The European Space Agency Exploration Programme Aurora," AIAA Paper No. 2005-2518, Jan. 2005.

[2] Hall, J.L., Noca, M.A., and Bailey, R.W., "Cost-Benefit Analysis of the Aerocapture Mission Set," Journal of Spacecraft and Rockets, Vol. 42, No. 2, 2005, pp. 309-320.

[3] Braun, R.D. and Manning, R.M., "Mars Exploration Entry, Descent and Landing Challenges," IEEE Aerospace Conference Paper No. 2006-1076, Mar. 2006.

[4] Striepe, S., Braun, R., Powell, R., and Fowler, W., "Influence of Interplanetary Trajectory Selection on Mars Atmospheric Entry Velocity," Journal of Spacecraft and Rockets, Vol. 30, No. 4, 1993, pp. 426-430.

[5] Braun, R.D., Powell, R.W., and Hartung, L.C., "Effect of Interplanetary Trajectory Options on a Manned Mars Aerobrake Configuration," NASA TP 3019, Aug. 1990. 
[6] Dyakonov, A., Edquist, K., and Shoenenberger, M., "Influence of the Angle of Attack on the Aerothermodynamic Environment of the Mars Science Laboratory," AIAA Paper No. 2006-3889, Jun. 2006.

[7] McDaniel, R.D., Wright, M.J., and Songer, J., "Aeroheating Predictions for Phoenix Entry Vehicle," AIAA Paper submitted to the Thermophysics summer conference, Miami, FL, Jun. 2007.

[8] Gnoffo, P., Weilmuenster, K., Braun, R., and Cruz C., "Influence of Sonic Line Location on Mars Pathfinder Probe Aerothermodynamics," Journal of Spacecraft and Rockets, Vol. 33, No. 2, 1996, pp. 169-177.

[9] Spencer, D., Blanchard, R., Braun, R., Kallemeyn, P., and Thurman, S., "Mars Pathfinder Entry, Descent and Landing Reconstruction," Journal of Spacecraft and Rockets, Vol. 36, No. 3, 1999, pp. 357-366.

[10] Chen, Y.-K., Henline, W.D., and Tauber, M.E., "Mars Pathfinder Trajectory Based Heating and Ablation Calculations," Journal of Spacecraft and Rockets, Vol. 32, No. 2, 1995, pp. 225-230.

[11] Gupta, R.N., Lee, K.P., and Scott, C.D., "Aerothermal Study of Mars Pathfinder Aeroshell," Journal of Spacecraft and Rockets, Vol. 33, No. 1, 1996, pp. 61-69.

[12] Moss, J. and Price, J., "Survey of Blunt Body Flows Including Wakes at Hypersonic Low Density Conditions," Journal of Thermophysics and Heat Transfer, Vol. 11, No. 3, 1997, pp. 321-329.

[13] Gnoffo, P.A., Gupta, R.N., and Shinn, J.L., "Conservation Equations and Physical Models for Hypersonic Air Flows in Thermal and Chemical Nonequilibrium," NASA TP 2867, Feb. 1989.

[14] Gnoffo, P., "Planetary Entry Gas Dynamics," Annual Review of Fluid Mechanics, Vol. 31, 1999, pp. 459-494.

[15] Park, C., "Assessment of Two-Temperature Kinetic Model for Air," Journal of Thermophysics and Heat Transfer, Vol. 3, No. 3, 1989, pp. 233-244.

[16] Millikan, R. and White, D., "Systematics of Vibrational Relaxation," Journal of Chemical Physics, Vol. 39, No. 12, 1963, pp. 3209-3213.

[17] Camac, M., " $\mathrm{CO}_{2}$ Relaxation Processes in Shock Waves," Fundamental Phenomena in Hypersonic Flow, ed. J.G. Hall, Cornell University Press, 1964, pp. 195-215.

[18] Park, C., Howe, J., Jaffe, R., and Candler, G., "Review of Chemical-Kinetic Problems of Future NASA Missions, II: Mars Entries," Journal of Thermophysics and Heat Transfer, Vol. 8, No.1, 1994, pp. 9-23.

[19] Taylor, R.L. and Bitterman, S., "Survey of Vibrational Relaxation Data for Processes Important in the $\mathrm{CO}_{2}$ $\mathrm{N}_{2}$ Laser System," Review of Modern Physics, Vol. 41, No. 1, 1969, pp. 26-47.

[20] Weitz, E. and Flynn, G., "Laser Studies of Vibrational and Rotational Relaxation in Small Molecules," Annual Review of Physical Chemistry, Vol. 25, Oct. 1974, pp. 275-315.

[21] Gordon, S. and McBride, B.J., "Computer Program for Calculation of Complex Chemical Equilibrium Compositions and Applications," NASA RP 1311, Oct. 1994.

[22] Capitelli, M., Colonna, G., Giordano, D., Marraffa, L., Casavola, A., Minelli, P., Pagano, D., Pietanza, L., and Taccogna, F., "High-Temperature Thermodynamic Properties of Mars-Atmosphere Components," Journal of Spacecraft and Rockets, Vol. 42, No. 6, 2005, pp. 980-989.

[23] Gurvich, L., Veyts, I., and Alcock, C., Thermodynamic Properties of Individual Substances, Hemisphere, New York, 1989.

[24] Mitcheltree, R.A., and Gnoffo, P.A., "Wake Flow about the Mars Pathfinder Entry Vehicle," Journal of Spacecraft and Rockets, Vol. 32, No. 5, 1995, pp. 771-776.

[25] Gupta, R., Yos, J., Thompson, R., and Lee, K., "A Review of Reaction Rates and Thermodynamic and Transport Properties for an 11-Species Air Model for Chemical and Thermal Nonequilibrium Calculations to 30000 K," NASA RP 1232, Aug. 1990.

[26] Palmer, G.E. and Wright, M.J., "A Comparison of Methods to Compute High Temperature Gas Viscosity," Journal of Thermophysics and Heat Transfer, Vol. 17, No. 2, 2003, pp. 232-239.

[27] Ramshaw, J.D., "Self-Consistent Effective Binary Diffusion in Multicomponent Gas Mixtures," Journal of Non-Equilibrium Thermodynamics, Vol. 15, No. 3, 1990, pp. 295-300.

[28] Sutton, K. and Gnoffo, P., "Multi Component Diffusion with Application to Computational Aerothermodynamics," AIAA Paper No. 98-2575, Jun. 1998.

[29] Papadopoulos, P., Prabhu, D., Olynick, D., Chen, Y.-K., and Cheatwood, F.M., "CFD Code Comparisons for Mars Entry Simulations," AIAA Paper No. 98-0272, Jan. 1998.

[30] Rini, P. and Degrez, G., "Elemental Demixing in Air and Carbon Dioxide Stagnation Line Flows," Journal of Thermophysics and Heat Transfer, Vol. 18, No. 4, 2004, pp. 511-518.

[31] Ramshaw, J. and Chang, C., "Ambipolar Diffusion in Multicomponent Plasmas," Plasma Chemistry and Plasma Processing, Vol. 11, No. 3, 1991, pp. 395-402.

[32] Wright, M.J., Bose, D., Palmer, G.E., and Levin E., "Recommended Collision Integrals for Transport Property Computations I: Air Species," AIAA Journal, Vol. 43, No. 12, 2005, pp. 2558-2564. 
[33] Wright, M.J., Hwang, H.H., and Schwenke, D.W., "Recommended Collision Integrals for Transport Property Computations II: Mars and Venus Entries," AIAA Journal, Vol. 45, No. 1, 2007, pp. 281-288.

[34] Baldwin, B. and Lomax, H., "Thin Layer Approximation and Algebraic Model for Separated Turbulent Flows," AIAA Paper No. 78-257, Jan. 1978.

[35] Menter, F.R., "Two-Equation Eddy-Viscosity Turbulence Models for Engineering Applications," AIAA Journal, Vol. 32, No. 8, 1994, pp. 1598-1605.

[36] Brown, J.L., "Turbulence Model Validation for Hypersonic Flows," AIAA Paper No. 2002-3308, Jun. 2002.

[37] Xiao, X., Edwards, J.R., Hassan, H.A., and Culter, A.D., "Variable Turbulent Schmidt Number Formulation for Scramjet Applications," AIAA Journal, Vol. 44, No. 3, 2006, pp. 593-599.

[38] Schneider, S.P., "Laminar-Turbulent Transition on Reentry Capsules and Planetary Probes," Journal of Spacecraft and Rockets, Vol. 43, No. 6, 2006, pp. 1153-1173.

[39] Tauber, M.E., "A Review of High-Speed Convective Heat Transfer Computation Methods," NASA TP-2914, Jul. 1989.

[40] Edquist, K., Liechty, D., Hollis, B., Alter, S., and Loomis, M., “Aeroheating Environments for a Mars Smart Lander," Journal of Spacecraft and Rockets, Vol. 43, No. 2, 2006, pp. 330-339.

[41] Reshotko, E., "Is Retheta/Me a Meaningful Transition Criterion?," AIAA Paper 2007-0943, Jan. 2007.

[42] Reshotko, E, Tumin, A. "Role of Transient Growth in Roughness-Induced Transition," AIAA Journal, Vol. 42, No. 4, 2004, pp. 766-770.

[43] Reda, D.C., "Review and Synthesis of Roughness-Dominated Transition Correlations for Reentry Applications," Journal of Spacecraft and Rockets, Vol. 39, No. 2, 2002, pp. 161-167.

[44] Demetriades, A., Laderman, A., Von Seggern, L., Hopkins, A., and Donaldson, J., "Effect of Mass Addition on the Boundary Layer of a Hemisphere at Mach 6," Journal of Spacecraft and Rockets, Vol. 13, No. 8, 1976, pp. 508-509.

[45] Johnson, H. and Candler, G., "Analysis of Laminar-Turbulent Transition in Hypersonic Flight Using PSEChem," AIAA Paper No. 2006-3057, Jun. 2006.

[46] Johnson, H., Candler, G., and Wright, M., "Boundary Layer Stability Analysis of Mars Science Laboratory Aeroshell," AIAA Paper No. 2006-0920, Jan. 2006.

[47] Reshotko, E., "Transition Issues at Hypersonic Speeds," AIAA Paper No. 2006-0707, Jan. 2006.

[48] Emmons, H.W. and Leigh, D., "Tabulation of the Blasius Function with Blowing and Suction," Harvard Univ. Combustion Aerodynamics Lab, Tech Rept. 9, 1953.

[49] Holden, M.S, "Experimental Studies of Surface Roughness, Entropy Swallowing and Boundary Layer Transition Effects on the Skin Friction and Heat Transfer Distribution in High Speed Flows," AIAA Paper No. 82-0034, Jan, 1982.

[50] Holden, M.S, "Studies of Surface Roughness and Blowing Effects on Hypersonic Turbulent Boundary Layers Over Slender Cones," AIAA Paper No. 89-0458, Jan, 1989.

[51] Moffat, R. and Kays, W., "A Review of Turbulent Boundary Layer Heat Transfer Research at Stanford, 19581983," Advances in Heat Transfer, Vol. 16, ed. Harnett, J.P. and Irvine, T.F., Academic Press, Inc. NY, 1984.

[52] Simpson, R.L., Kays, W.M., and Moffat, R.J., "The Turbulent Boundary Layer on a Porous Plate: An Experimental Study of the Fluid Dynamics with Injection and Suction," Rept. HMT-2, Mechanical Engineering Dept., Stanford Univ.

[53] Cebeci, T. and Bradshaw, P., Physical and Computational Aspects of Convective Heat Transfer, SpringerVerlag, NY, 1984.

[54] Wilcox, D.C., Turbulence Modeling for CFD, $3^{\text {rd }}$ Edition, DCW Industries, La Canada, CA, 2006.

[55] Chen, Y.-K. and Milos, F.S., "Ablation and Thermal Response Program for Spacecraft Heatshield Analysis," AIAA Paper No. 98-0273, Jan. 1998.

[56] Park, C., "Injection Induced Turbulence in Stagnation Point Boundary Layers," AIAA Journal, Vol. 22, No. 2, 1984, pp. 219-225.

[57] Berg, D.E., "Surface Roughness Effects on a Mach 6 Turbulent Boundary Layer," AIAA Paper No. 78-1159, Jul. 1978.

[58] Reda, D.C., Ketter, F.C., and Fan C., "Compressible Turbulent Skin Friction on Rough and Rough/Wavy Walls," AIAA Journal, Vol. 13, No. 5, 1975, pp. 553-554.

[59] Dahm, T.J., "Passive Nosetip Technology (PANT II) Program," SAMSO TR 77-11, Oct. 1976, Acurex Corp., Mountain View, CA.

[60] Dirling, R.B., "A Method for Computing Roughwall Heat Transfer Rates on Reentry Nosetips," AIAA Paper No. 73-0762, Jun. 1973.

[61] Wilson, L., "Far Wake Behavior of Hypersonic Spheres," AIAA Journal, Vol. 5, No. 7, 1967, pp. 1238-1244. 
[62] Nance, R.P., Hollis, B.R., Horvath, T.J., Alter, S.J., and Hassan, H.A., "Computational Study of Hypersonic Transitional Wake Flows," Journal of Thermophysics and Heat Transfer, Vol. 13, No. 2, 1999, pp. 236-242.

[63] Lees, L., "Hypersonic Wakes and Trails," AIAA Journal, Vol. 2, No. 3, 1964, pp. 417-428.

[64] Holden, M.S., "Experimental Studies of the Effect of Mass Addition on the Low-Altitude Turbulent Wake Behind Sharp Slender Cones," AIAA Paper No. 91-1774, Jun. 1991.

[65] Forsythe, J.R., Hoffman, K.A., Cummings, R.M., and Squires, K.D., "Detached Eddy Simulation with Compressibility Corrections Applied to a Supersonic Axisymmetric Base Flow," Journal of Fluids Engineering, Vol. 124, Dec. 2002.

[66] Barnhardt, M. and Candler, G., "Detached Eddy Simulation of Hypersonic Base Flows During Atmospheric Entry," AIAA Paper No. 2006-3575, Jun. 2006.

[67] Papadopoulos, P., Tauber, M., and Chang, I.-D., "Heat Shield Erosion in a Dusty Martian Atmosphere," Journal of Spacecraft and Rockets, Vol. 30, No. 2, 1993, pp.140-151.

[68] Palmer, G., Chen, Y.-K., Papadopoulos, P., and Tauber, M., "Reassessment of Effect of Dust Erosion on Heatshield of Mars Entry Vehicle," Journal of Spacecraft and Rockets, Vol. 37, No. 6, 2000, pp. 747-752.

[69] Fertig, M., Schäff, S., Herdrich, G., and Auweter-Kurtz, M., "Influence of Chemical Accomodation on Reentry Heating and Plasma Wind Tunnel Experiments," AIAA Paper No. 2006-3816, Jun. 2006.

[70] Stewart, D.A., "Determination of Surface Catalytic Efficiency for Thermal Protection Materials: Room Temperature to Their Upper Use Limit," AIAA Paper No. 96-1863, Jun. 1996.

[71] Kolesnikov, A. and Marraffa, L., "An Analysis of Stagnation Point Thermochemical Simulation by Plasmatron for Mars Probe," AIAA Paper No. 99-3564, Jun. 1999.

[72] Kolesnikov, A., Pershin, I.S., Vasilandapos'evskii, S., and Yakushin, M.I., "Study of Quartz Surface Catalycity in Dissociated Carbon Dioxide Subsonic Flows," Journal of Spacecraft and Rockets, Vol. 37, No. 5, 2000, pp. 573-579.

[73] Sepka, S., Chen, Y.-K., Marschall, J., and Copeland, R., "Experimental Investigation of Surface Reactions in Carbon Monoxide and Oxygen Mixtures," Journal of Thermophysics and Heat Transfer, Vol. 14, No. 1, 2000, pp. 45-52.

[74] Afonina, N.E., Gromov, V.G., and Kovalev, V.L., "Catalysis Modeling for Thermal Protection Systems of Vehicles Entering into Martian Atmosphere," AIAA Paper No. 2001-2832, Jun. 2001.

[75] Rini, P., Garcia, A., Magin, T., and Degrez, G., "Numerical Simulation of $\mathrm{CO}_{2}$ Nonequilibrium Flows with Catalyzed Surface Reactions," Journal of Thermophysics and Heat Transfer, Vol. 18, No. 4, 2004, pp. 511518.

[76] Marschall, J., Copeland, R., Hwang, H., and Wright, M., "Surface Catalysis Experiments on Metal Surfaces in Oxygen and Carbon Monoxide Mixtures," AIAA Paper No. 2006-0181, Jan. 2006.

[77] Edquist, K., Dyakonov, A., Wright, M., Tang, C., "Aerothermodynamic Environments Definition for the Mars Science Laboratory Entry Capsule," AIAA Paper No. 2007-1206, Jan. 2007.

[78] Mitcheltree, R.A., "Computational Aerothermodynamics for Mars Pathfinder Including Turbulence," AIAA Paper No. 95-3493, Aug. 1995.

[79] Kissel-Osterrieder, R., Behrendt, F., Warnatz, J., Metka, U., Volpp, H., and Wolfrum, J., "Experimental and Theoretical Investigation of CO Oxidation on Platinum: Bridging the Pressure and Materials Gap," Proceedings of the Combustion Institute, Vol. 28, 2000, pp. 1341-1348.

[80] Bose, D., Wright, M.J., and Palmer, G.E., "Uncertainty Analysis of Laminar Aeroheating Predictions for Mars Entries," Journal of Thermophysics and Heat Transfer, Vol. 20, No. 4, 2006, pp. 652-662.

[81] Park, C., "Effects of Atomic Oxygen on Graphite Ablation," AIAA Journal, Vol. 14, No. 11, 1976, pp. 16401642.

[82] Milos, F.S. and Rasky, D.J., "Review of Numerical Procedures for Computational Surface Thermochemistry," Journal of Thermophysics and Heat Transfer, Vol. 8, No. 1, 1994, pp. 24-34.

[83] Chen, Y.-K. and Milos, F., "Navier-Stokes Solutions with Finite Rate Ablation for Planetary Mission Earth Reentries," Journal of Spacecraft and Rockets, Vol. 42, No. 6, 2005, pp. 961-970.

[84] Brown, J.L., "The Effect of Forebody Geometry on Turbulent Heating and Thermal Protection System Sizing for Future Mars Mission Concepts," Proceedings of the $4^{\text {th }}$ International Planetary Probe Workshop, Pasadena, CA, Jun. 2006.

[85] Wright, H., Oh, D., Westhelle, C., Fisher, J., Dyke, R., Edquist, K., Brown, J., Justh, H., and Munk, M., "Mars Aerocapture Systems Study," NASA TM 2006-214522, Aug. 2006.

[86] Wright, M.J., Milos, F.S., and Tran, P., "Survey of Afterbody Aeroheating Flight Data for Thermal Protection System Design," Journal of Spacecraft and Rockets, Vol. 43, No. 5, 2006, pp 929-943. 
[87] Horvath, T.J., Heiner, N.C., and Olguin, D.M., "Wake Closure and Afterbody Heating on a Mars Sample Return Orbiter," Journal of Spacecraft and Rockets, Vol. 41, No. 5, 2004, pp. 705-715.

[88] Liechty, D., Hollis, B., and Edquist, K., "Mars Science Laboratory Experimental Aerothermodynamics with Effects of Cavities and Control Surfaces," Journal of Spacecraft and Rockets, Vol. 43, No. 2, 2006, pp. 340353.

[89] Reda, D., Wilder, M., Bogdanoff, D., and Olejniczak, J., “Aerothermodynamic Testing of Ablative Reentry Vehicle Nosetip Materials in Hypersonic Ballistic-Range Environments," AIAA Paper No. 2004-6829, Nov. 2004.

[90] Haas, B.L. and Venkatapathy, E.V., "Mars Pathfinder Computations Including Base Heating Predictions," AIAA Paper No. 95-2086, Jun. 1995.

[91] Martin-Marietta Corp., "Entry Data Analysis for Viking 1 and 2," NASA CR 159388, Nov. 1976.

[92] Morabito, D. and Edquist, K., "Communications Blackout Predictions for Atmospheric Entry of Mars Science Laboratory," IEEE Aerospace Conference Paper No. 2005-1163, Mar. 2005.

[93] Edquist, K.T., "Afterbody Heating Predictions for a Mars Science Laboratory Vehicle," AIAA Paper No. 2005-4817, Jun. 2005.

[94] Edquist, K.T., Wright, M.J., and Allen, G.A., "Viking Afterbody Heating Computations and Comparisons to Flight Data," AIAA Paper No. 2006-0386, Jan. 2006.

[95] Olynick, D.R., Chen, Y.-K., and Tauber, M.E., "Aerothermodynamics of the Stardust Sample Return Capsule," Journal of Spacecraft and Rockets, Vol. 36, No. 3, 1999, pp. 442-462.

[96] Hartung, L., Sutton, K., and Brauns, F., "Equilibrium Radiative Heating Tables for Aerobraking in the Martian Atmosphere," NASA TM-102659, May 1990.

[97] Tauber, M.E. and Sutton, K., "Stagnation Point Radiative Heating Relations for Earth and Mars Entries," Journal of Spacecraft and Rockets, Vol. 28, No. 1, 1991, pp. 40-42.

[98] Whiting, E.E., Yen, L., Arnold, J.O., and Paterson, J., "NEQAIR96, Nonequilibrium and Equilibrium Radiative Transport and Spectra Program: User's Manual," NASA RP-1389, Dec. 1996.

[99] Olynick, D., Henline, W., Hartung-Chambers, L., and Candler, G., "Comparison of Coupled Radiative Flow Solutions with Project Fire II Flight Data," Journal of Thermophysics and Heat Transfer, Vol. 9, No. 4, 1995, pp. 586-594.

[100] Ramjaun, D., Dumitrescu, M., and Brun, R., "Kinetics of Free Radicals Behind Strong Shock Waves," Journal of Thermophysics and Heat Transfer, Vol. 13, No. 2, 1999, pp. 219-225.

[101] Kudryavtsev, N., Kuznetsova, L., and Surzhikov, S., "Kinetics and Nonequilibrium Radiation of $\mathrm{CO}_{2}-\mathrm{N}_{2}$ Shock Waves," AIAA Paper No. 2001-2728, Jun. 2001.

[102] Zalogin, G., Kozlov, P., Kuznetsova, L., Losev, S., Makarov, V., Romanenko, Y., and Surzhikov, S., "Radiation Excited by Shock Waves in a $\mathrm{CO}_{2}-\mathrm{N}_{2}$-Ar Mixture: Experiment and Theory," Technical Physics, Vol. 71, No. 6, 2001, pp. 10-16.

[103] Anohin, E., Ivanova, T., Koudriavtsev, N., and Starikovskii. A., "Nonequilibrium Radiation Investigation Behind the Strong Shock Waves in $\mathrm{CO}_{2}: \mathrm{N}_{2}$ :Ar Mixtures," AIAA Paper No. 2005-0792, Jan. 2005.

[104] Bose, D., Wright, M., Raiche, G., Bogdanoff, D., and Allen, G., "Modeling and Experimental Validation of CN Radiation Behind a Strong Shock Wave," Journal of Thermophysics and Heat Transfer, Vol. 20, No. 2, 2006, pp. 220-230.

[105] Milos, F., Chen, Y.-K., Congdon, W., and Thornton, J., "Mars Pathfinder Entry Temperature Data, Aerothermal Heating, and Heatshield Material Response," Journal of Spacecraft and Rockets, Vol. 36, No. 3, 1999, pp. 380-391.

[106] Szalai, C., Chen, Y.-K., Loomis, M., Thoma, B., and Buck, S., "Mars Exploration Rover Transverse Impulse Rocket Cover Thermal Protection System Design Verification," Journal of Spacecraft and Rockets, Vol. 42, No. 6, 2005, pp. 990-998.

[107] Bose, D., Wright, M.J., and Gökçen, T., "Uncertainty and Sensitivity Analysis of Thermochemical Modeling for Titan Atmospheric Entry," AIAA Paper No. 2004-2455, Jun. 2004.

[108] Hollis, B.R. and Perkins, J.N., "High-Enthalpy Aerothermodynamics of a Mars Entry Vehicle, Part 1: Experimental Results," Journal of Spacecraft and Rockets, Vol. 34, No. 4, 1997, pp. 449-456.

[109] Hollis, B.R. and Perkins, J.N., "High-Enthalpy Aerothermodynamics of a Mars Entry Vehicle, Part 2: Computational Results," Journal of Spacecraft and Rockets, Vol. 34, No. 4, 1997, pp. 457-463.

[110] Liechty, D.S., and Hollis, B.R. "Heat Shield Cavity Parametric Experimental Aeroheating for a Proposed Mars Smart Lander Aeroshell," AIAA Paper No. 2002-2746, Jun. 2002.

[111] Hollis, B.R. and Liechty, D.S., "Transition Due to Heat Shield Cavities on a Mars Entry Vehicle," Journal of Spacecraft and Rockets, Vol. 43, No. 2, 2006, pp. 354-366. 
[112] Hollis, B., Liechty, D., Wright, M., Holden, M., Wadhams, T., MacLean, M., and Dyakonov, A., "Transition Onset and Turbulent Heating Measurements for the Mars Science Laboratory Entry Vehicle," AIAA Paper No. 2005-1437, Jan. 2005.

[113] Hollis, B. and Collier, A., "Turbulent Aeroheating Testing of Mars Science Laboratory Entry Vehicle in Nitrogen," AIAA Paper No. 2007-1208, Jan. 2007.

[114] Wright, M.J., Olejniczak, J., Brown, J.L., Hornung, H., and Edquist, K.T., "Modeling of Shock Tunnel Aeroheating Data on the Mars Science Laboratory Aeroshell," Journal of Thermophysics and Heat Transfer, Vol. 20, No. 4, 2006, pp. 641-651.

[115] MacLean, M., Wadhams, T., Holden, M., and Hollis, B., "Investigation of Blunt Bodies with $\mathrm{CO}_{2}$ Test Gas Including Catalytic Effects," AIAA Paper No. 2005-4693, Jun. 2005.

[116] MacLean, M. and Holden, M., "Catalytic Effects on Heat Transfer Measurements for Aerothermal Studies with $\mathrm{CO}_{2}$," AIAA Paper No. 2006-0182, Jan. 2006.

[117] MacLean, M. and Holden, M., "Numerical Assessment of Data in Catalytic and Transitional Flows for Martian Entry," AIAA Paper No. 2006-2946, Jun. 2006.

[118] Nompelis, I., Candler, G., and Holden, M., "Effect of Vibrational Nonequilibrium on Hypersonic Double Cone Experiments," AIAA Journal, Vol. 41, No. 11, 2003, pp. 2162-2169.

[119] Faye-Petersen, R., Sarver, D., and Carroll, H., "Heat Transfer and Pressure Distributions at $\mathrm{M}=8$ on 0.028 Scale Models of the Viking Entry Vehicle," NASA CR 132413, Jul. 1972.

[120] Martin-Marietta Corp., "Viking Lander System, Primary Mission Performance Report," NASA CR 145148, Apr. 1977.

[121] Schmitt, D., "Base Heating on an Aerobraking Orbital Transfer Vehicle," AIAA Paper 83-0408, Jan. 1983.

[122] Willcockson, W.H., "Mars Pathfinder Heatshield Design and Flight Experience," Journal of Spacecraft and Rockets, Vol. 36, No. 3, 1999, pp. 374-379.

[123] Szalai, C., Lee, W., Thoma, B., Maki, J., Willcockson, W., and Venkatapathy, E., "MER Heatshield Observation Campaign," Proceedings of the $3^{\text {rd }}$ International Planetary Probe Workshop, ESA Publication WPP-263, Mar. 2006.

[124] Desai, P.N., Shoenenberger, M., and Cheatwood, F.M., "Mars Exploration Rover Six Degree-of-Freedom Entry Trajectory Analysis," Journal of Spacecraft and Rockets, Vol. 43, No. 5, 2006, pp. 1019-1025.

[125] Oishi, T., Martinez, E., Fu, J., Gorbunov, S, and Congdon, W., "Current Developments in Future Planetary Probe Sensors for TPS: Heatshield Ablation Detector Adaptation to Mid Density Ablators," Proceedings of the $3^{\text {rd }}$ International Planetary Probe Workshop, ESA Publication WPP-263, Mar. 2006.

[126] Gazaric, M., Hwang. H.H., Cheatwood, F.M., and Wright, M.J., "Overview of the MSL Entry Descent and Landing Instrumentation (MEDLI) Project Objectives," to be published in the Proceedings of the $5^{\text {th }}$ International Planetary Probe Workshop, June 21-25, 2007, Bordeaux, France.

[127] Hurt, D., Encyclopedia of Soviet Spacecraft, Exeter Books, New York, 1987.

[128] Perminov, V.G., "The Difficult Road to Mars: A Brief History of Mars Exploration in the Soviet Union," Monographs in Aerospace History, No. 15, Jul. 1999.

[129] Queen, E., Cheatwood, F., Powell, R., Braun, R., and Edquist, C., "Mars Polar Lander Aerothermodynamic and Entry Dispersion Analysis," Journal of Spacecraft and Rockets, Vol. 36, No. 3, 1999, pp. 421-428.

[130] Mitcheltree, R.A., DiFulvio, M., Horvath, T.J., and Braun, R.D., "Aerothermal Heating Predictions for Mars Microprobe," AIAA Paper 98-0170, Jan. 1998.

[131] Smith, A., Parnaby G., Jones T., and Buttsworth D., "Aerothermal Environment of the Beagle 2 Probe," Proceedings of the $4^{\text {th }}$ European Symposium on Aerothermodynamics, Capua, Italy, Oct. 2001.

[132] Roncoli, R.B. and Ludwinski, J.M., "Mission Design Overview for the Mars Exploration Rover Mission," AIAA Paper No. 2002-4823, Aug. 2002.

[133] Edquist, K.T., Dyakonov, A.A., Wright, M.J., and Tang, C.Y., "Aerothermodynamic Design of the Mars Science Laboratory Backshell and Parachute Cone," AIAA Paper No. 2009-4078, Jun. 2009.

[134] Wright, M.J., Bose, D., and Chen, Y.-K., "Probabilistic Modeling of Aerothermal and Thermal Protection Material Response Uncertainties," AIAA Journal, Vol. 45, No. 2, 2007, pp. 399-410.

[135] Cheatwood, F.M. and Gnoffo, P.A., "Users Manual for the Langley Aerothermal Upwind Relaxation Algorithm (LAURA)," NASA TM-4674, April 1996.

[136] Wright, M.J., White, T., and Mangini, N., "Data Parallel Line Relaxation (DPLR) Code User Manual; Acadia - Version 4.01.1," NASA TM 2009-215388, Oct. 2009.

[137] Edquist, K.T., Dyakonov, A.A., Wright, M.J., and Tang, C.Y., "Aerothermodynamic Design of the Mars Science Laboratory Heatshield," AIAA Paper No. 2009-4075, Jun. 2009. 
[138] Beck, R., Driver, D., Wright, M., Laub, B., Slimko, E., Edquist, K., Thames, T., Willcockson, W., Sepka, S., and Hwang, H., "Development of the MSL Heatshield TPS," AIAA Paper No. 2009-4229, Jun. 2009.

[139] Dyakonov, A.A., Glass, C.E., and Desai P.N., "Analysis of Effectiveness of Phoenix Entry Reaction Control System," AIAA Paper No. 2008-7220, Aug. 2008.

[140] Tang, C.Y., Wright, M.J., Edquist K.T., Sepka S., and Cassel, A., "Numerical Simulations of Protruding Gap Fillers on the Mars Science Laboratory Heatshield," AIAA Paper No. 2009-4077, Jun. 2009.

[141] Wright, M., Beck, R., Edquist K., Driver, D., Sepka S., Slimko, E., Willcockson, W., DeCaro, T., and Hwang, H., "Sizing and Margins Assessment of the Mars Science Laboratory Aeroshell Thermal Protection System," AIAA Paper No. 2009-4231, Jun. 2009.

[142] Bose, D., "Hypersonic Aerodynamics, Aerothermodynamics and Plasmadynamics Research Activities Within NASA's Fundamental Aeronautics Program," AIAA Paper No. 2009-7278, Oct. 2009.

[143] Anderson, B., "BLT Flight Experiment Overview and In-Situ Measurements," AIAA Paper No. 2010-0240, Jan. 2010.

[144] Barnhardt, M.D. and Candler, G.V., "CFD Analysis of CUBRC Base Flow Experiments," AIAA Paper No. 2010-1250, Jan. 2010.

[145] Johnston, C., "A Study of Ablation-Flowfield Coupling Relevant to Orion Heatshield," AIAA Paper No. 2009-4318, Jun. 2009.

[146] Cruden, B., Martinez, R., Grinstead, J., and Olejniczak, J., "Simultaneous Vacuum Ultraviolet Through Near IR Absolute Radiation Measurement with Spatiotemporal Resolution in an Electric Arc Shock Tube," AIAA Paper No. 2009-4240, Jun. 2009.

[147] MacLean, M., Dufrene, A., Wadhams, T., and Holden, M., "Numerical and Experimental Characterization of High Enthalpy Flow in an Expansion Tunnel Facility," AIAA Paper No. 2010-1562, Jan. 2010.

[148] Hollis, B., Berger, K., Horvath, T., Coblish, J., Norris, J., Lillard, R., Kirk, B., "Aeroheating Testing and Predictions for Project Orion Crew Exploration Vehicle," Journal of Spacecraft and Rockets, Vol. 46, No. 4, 2009, pp. 766-780.

[149] Chang, C.L., Choudhari, M.M., Hollis, B.R., and Li, F., "Transition Analysis for the Mars Science Laboratory Entry Vehicle," AIAA Paper No. 2009-4076, Jun. 2009.

[150] Johnson, H., "Orbiter Boundary Layer Stability Modeling at Flight Conditions," AIAA Paper No. 2010-xxxx, Jan. 2010.

[151] Tauber, M.E., Trumble, K.A., and Wright, M.J., "Cone Angle Choices for Atmospheric Entry Probes: A Review," Proceedings of the $6^{\text {th }}$ International Planetary Probe Workshop, Jun. 2008. 